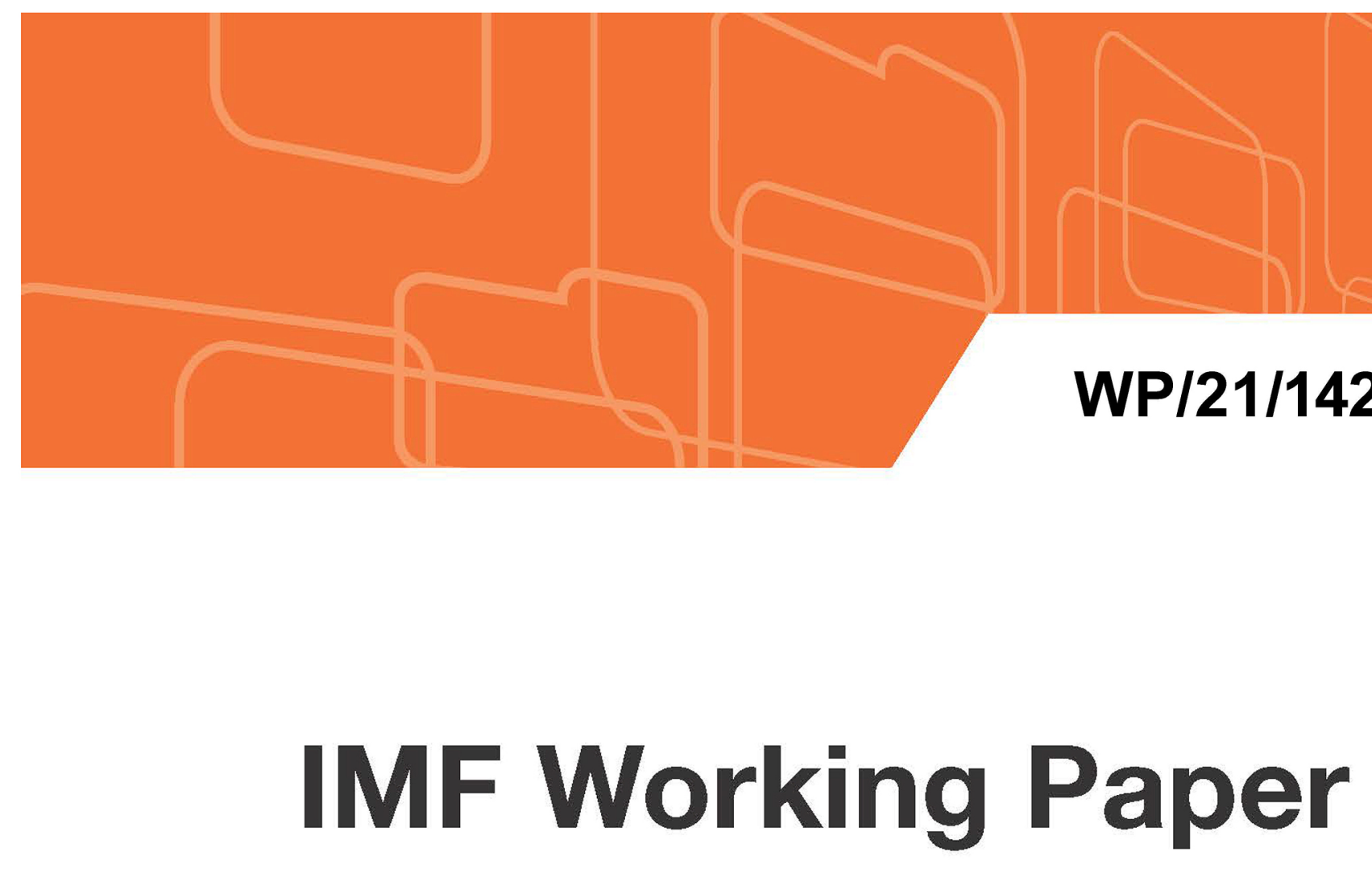

\title{
Labor Market Reforms and Earnings Dynamics: the Italian Case
}

By Eran B. Hoffmann, Davide Malacrino and Luigi Pistaferri 


\title{
IMF Working Paper
}

Research Department

\section{Labor Market Reforms and Earnings Dynamics: the Italian Case}

\author{
Authorized for distribution by Oya Celasun
}

May 2021

IMF Working Papers describe research in progress by the author(s) and are published to elicit comments and to encourage debate. The views expressed in IMF Working Papers are those of the author(s) and do not necessarily represent the views of the IMF, its Executive Board, or IMF management.

\begin{abstract}
This paper summarizes statistics on the key aspects of the distribution of earnings levels and earnings changes using administrative (social security) data from Italy between 1985 and 2016. During the time covered by our data, earnings inequality and earnings volatility increased, while earnings mobility did not change significantly. We connect these trends with some salient facts about the Italian labor market, in particular the labor market reforms of the 1990s and 2000s which induced a substantial rise in fixedterm and part-time employment. The rise in parttime work explains much of the rise in earnings inequality, while the rise in fixed-term contracts explains much of the rise in volatility. Both these trends affect the earnings distribution through hours worked: part-time jobs reduce hours worked within a week, while fixed-term contracts reduce the number of weeks worked during the year as well as increase their volatility. We find weak evidence that fixed-term contracts represent a "stepping-stone" to permanent employment. Finally, we offer suggestive evidence that the labor market reforms contributed to the slowdown in labor productivity in Italy by delaying human capital accumulation (in the form of general and firm-specific experience) of recent cohorts.
\end{abstract}

JEL Classification Numbers: J3, E2

Keywords: Labor Markets, Structural Reforms, Inequality

Author's E-Mail Address: eranhoff@,stanford.edu, dmalacrino@imf.org, pista@,stanford.edu. 


\section{TABLE OF \\ CONTENTS}

1. Introduction ___________

2. Institutional Background and Data___________ 4

2.1. Labor force participation, Unemployment and Labor Market reforms ____

2.2. Data___ 6

2.3. INPS labor force trends and comparisons with official statistics ___ 7

3. Core statistics ___

3.1. Inequality ___

3.2. Top shares ___

3.3. Inequality trends across cohorts _______

3.4. Volatility____ 14

3.5. Heterogeneity in measures of volatility ___ _ _ 16

3.6. Mobility ___

4. What drives the trends? ___ 20

4.1. Decomposing annual earnings: Hours and wages ___

4.2. Turnover and volatility _____ 23

4.3. Are fixed-term contracts stepping stones to permanent jobs?____ 24

4.4. Employment, human capital, and the slowing down of productivity growth ___ 28

5. Conclusions ___

\section{FIGURES}

Figure 1. Labor productivity growth, Italy vs G7 average

Figure 2. Labor market trends in the INPS dataset

Figure 3. Percentiles of the earnings distribution

Figure 4. Inequality ___ 11

Figure 5. Adjusted and unadjusted estimates of top income shares ___ 12

Figure 6. Decompose inequality by cohort ___ 13

Figure 7. Volatility and its upside/downside decomposition

Figure 8. Asymmetrical and central tendencies of earnings growth ___

Figure 9 . Volatility by cohort__ $\underline{16}$

Figure 10. Volatility measures by income percentile __ 17

Figure 11. Mobility____ 19

Figure 12. Mobility trends ___ 20

Figure 13. Counterfactual decomposition of earnings, demographic factors vs. job characteristics 21

Figure 14. Decomposition into hours worked and hourly earnings_____ _ _ 23

Figure 15. Shares of fixed-term contracts and intermittent workers, by cohort___ 27

Figure 16. Components of human capital___ 29

Figure 17. Human capital stock ______ 


\section{TABLES}

Table 1. Volatility $\underline{25}$

Table 2 . The probability of working on open-ended contract between age 27 and 35

\section{APPENDIX}

APPENDIX A.1 Other form of employment: public sector and self-employment a. 1

APPENDIX A.2 Top income share estimation in right censored data a. 2 APPENDIX A.3 Additional figures 
Note: Thanks to Rachel van Elkan, Gianluca Violante and to conference participants at Stanford, Minnesota (virtual conference) and IMF seminar for useful comments. All errors are ours. 


\section{Introduction}

This paper has two goals. The first is to provide key statistics on the evolution of the distribution of earnings levels and earnings growth rates in Italy between 1985 and 2016. The focus is on trends in earnings inequality, volatility, and mobility. This effort is a part of the cross-country project on "Global Income Dynamics" featured in a special issue of Quantitative Economics planned from 2022. We document a significant rise in common measures of inequality and volatility, while earnings mobility does not change significantly over the sample period. The rise in inequality is mostly driven by a decline in earnings in the bottom part of the distribution. The volatility of earnings, captured by measures of dispersion in earnings growth rates, is concentrated in the cohorts of workers who entered the labor market after 2000.

The second goal of the paper is to explore the role of key institutional elements of the Italian labor market in shaping these trends. A string of structural labor market reforms, starting in the mid-1990s, gradually transformed the nature of a job for many Italian workers, increasing the fraction of workers employed through atypical (part-time or fixed-term) contracts and creating a de facto dual labor market. We document that the rise in part-time work explains much of the rise in earnings inequality, while the rise in fixed-term contracts explains much of the rise in volatility. Both these trends affect the earnings distribution through hours worked: part-time jobs reduce hours worked within a week, while fixed-term contracts reduce the number of weeks worked during the year and increase their volatility.

The increase in the prevalence of fixed-term contracts (from $8 \%$ in 1998 to $18 \%$ of all employment contracts in 2016) raises the question of whether such contracts are a "stepping stone" for marginal workers entering the labor force, or rather a permanent shift towards jobs lacking traditional forms of employment protection. Cohort analysis shows that fixed-term contracts are substantially more prevalent among cohorts entering the labor market after 2000. Moreover, analysis of the effect of separations on earnings volatility at the individual level shows that the increase in earnings volatility associated to the end of a fixed-term contract is as large as the increase associated with a layoff. ${ }^{1}$ We find that, controlling for observable characteristics, workers who make an early start in their careers through fixed-term contract do not improve (and if anything, worsen) their chances of securing an open-ended contract by the end of their first decade in the labor market. This is suggestive evidence that early transitions into the labor market via fixed-term contracts do not provide workers with higher opportunities to transition to more stable employment later in their life cycle.

Are these micro facts related to macroeconomic trends? According to a variety of statistics, the Italian economy is particularly weak among the economies of the countries in of the Group of Seven (G7), a club of large developed economies of which Italy is a member. Figure 1 reports one such statistic, labor productivity, defined as GDP per hour worked, in Italy and in the whole G7. Labor productivity growth in Italy was half as large as in the G7 during the sample period. More

\footnotetext{
${ }^{1}$ This might become especially relevant in the aftermath if the COVI-19 pandemic, as by the end of 2020 job separations have mostly affetcted workers with temporary or part time contracts.
} 
telling to the unique economic situation is the divergence of the trends. For the first ten years or so, Italy and the other G7 countries marched in lockstep; after the mid-1990s, labor productivity kept increasing in the rest of the G7 but has come to a complete halt in Italy. The structural labor reforms that followed are commonly viewed as a policy response to this stagnation in labor productivity. $^{2}$

This stagnation of labor productivity is especially puzzling given the gradual, albeit slow, improvements in educational attainment in Italy and the technological developments of the last three decades. Several studies attempt to explain this divergence. Boeri and Garibaldi (2007) argue that the labor reforms made jobs more flexible, which expanded employment by adding less productive jobs, and thus reduced average labor productivity. Pellegrino and Zingales (2017) argue that most of the differences between Italy and other advanced economies can be attributed to the failure of Italian firms to adopt information and communication technologies, and trace the origin of the failure to the structure of firm ownership and cronyism. The high share of small firms in Italy could also explain why productivity has grown more slowly than in other advanced economies. Alternative channels include the exposure to the China trade shock (Bugamelli, Fabiani, Federico, Felettigh, Giordano, and Linarello, 2017)and the decline in the quality of economic institutions and government efficiency (Giordano, Lanau, Tommasino, and Topalova, 2015).

The analysis in this paper highlights another channel in which changes in the composition of job types, rather than changes in the composition of workers or their number, reduces labor productivity. Specifically, the rise in part-time work and fixed-term contracts among young workers reduces substantially the accumulation of work experience in the first decades of a career. We document that the cohort born in the 1980s had accumulated $15 \%$ less work experience than previous cohorts (the equivalent of a full year of work) by the time they reached age 35 . The tenure of young workers with their current employer has also declined. As Rosolia and Torrini (2007) point out, the temporary nature of the jobs of early career workers may reduce the incentives of firms to train them on the job, which further slows the accumulation of firm-specific human capital. These structural changes delay accumulation of human capital (in the form of reduced general and firm-specific experience) and form a gap in labor productivity between old and young workers.

In the rest of the paper, in Section 2 we provide some institutional background and present the data we use in the rest of the analysis. In Section 3 we present the key statistics about the earnings distribution in Italy for the 1985-2016 period. Section 4 offers an interpretation of the trends, focusing in particular on the role of labor market reforms. Section 5 concludes.

\footnotetext{
${ }^{2}$ This gradual fall in productivity growth is known in Italy as the "declino economico" (economic decline). The impact of the decline on Italian workers has been even more severe, as the labor share of national income declined from 0.79 to 0.69 between 1985-2012 (see OECD, https://stats.oecd.org/Index.aspx?queryname=345\&querytype=view\#; Unit Labour Costs - Annual Indicators : Labour Income Share Ratios).
} 


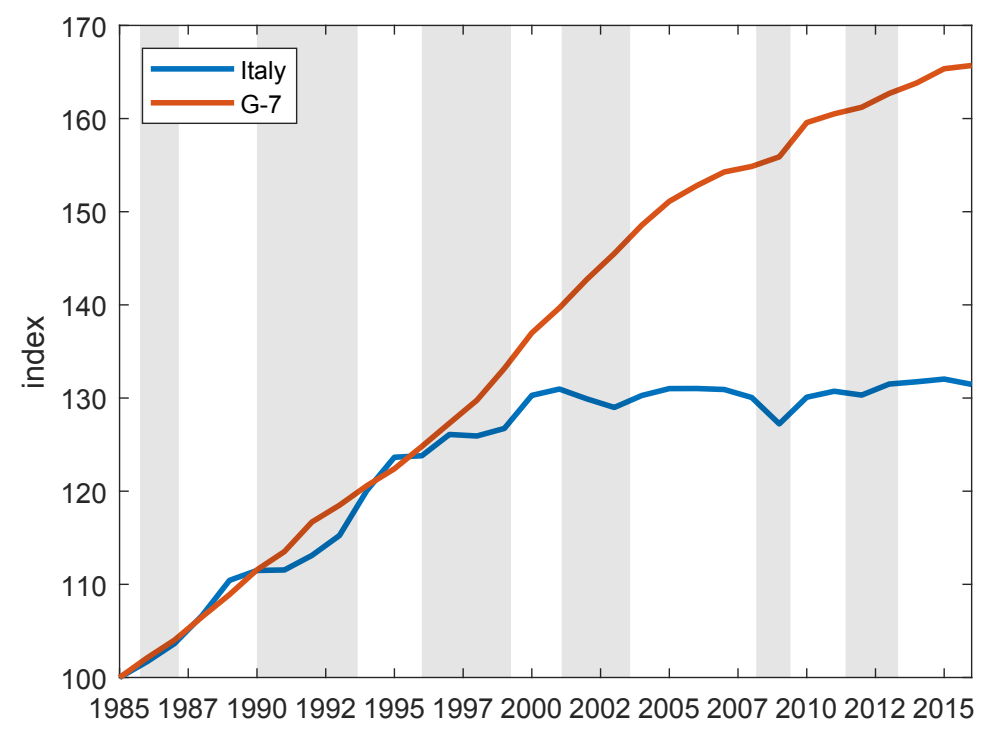

Figure 1: Labor productivity growth, Italy vs. G7 average

\section{Institutional Backgroundand Data}

Given that we link salient facts about trends in the earnings distribution with institutional changes in the Italian labor market, we start with a description of the latter.

\subsection{Labor force participation, Unemployment and Labor market reforms}

The Italian labor market underwent important structural changes during the period covered by our data. The first important trend, common to many other countries, is the decline in participation among men and the rise among women. Focusing on workers aged 25-54 (to be consistent with the age selection of our sample, detailed below), the labor force participation rate among men has declined from $95 \%$ in 1985 to $88 \%$ in 2016; during the same time period labor force participation among women has expanded from $48 \%$ in 1985 to $67 \%$ in 2016 (all these statistics come from the OECD). Persistently high unemployment rates in the 1980s and early 1990s, especially among marginal workers (youth and women), led to a string of structural labor reforms that, starting in the mid-1990s, reshaped the Italian labor market from one of the most rigid to, in some respects, one of the most flexible in Europe (at least for entry-level workers). The most significant reforms were: the "Social Pact" of 1993, the "Treu reform" of 1997, the "Biagi reform" of 2003, the "Fornero reform" of 2012, and the "Poletti decree" and the Jobs Act, both passed in 2014.

The "Social Pact" reformed the collective bargaining system (adding a firm-bargaining layer to the national one) and eliminated the automatic indexation of wages to inflation ("scala mobile"). The "Treu reform" liberalized the entry wages for first-job seekers and reduced the constraints 
preventing firms to use fixed-term labor contracts or part-time workers. The "Biagi reform" introduced a wide variety of atypical employment contracts, such as on-call jobs (lavoro intermittente), job sharing, and occasional employment (lavoro a progetto). ${ }^{3}$ The "Fornero reform" widened the range of applicability of temporary employment, while introducing limits to its use and duration (fixed-term contracts could only be renewed once and have maximum 36 months duration). The "Poletti decree", however, went into the opposite direction. Firms could use fixed-term contracts with no obligation of justifying their use and renew them for up to five times. The only new constraint was the requirement that the ratio of fixed-term contracts to open-ended contracts would not exceed $20 \%$. The final reform (the Jobs Act) changed the nature of open-ended contracts by reducing protection against "just cause" dismissals. It introduced a new, intermediate employment contract (contratto a tutele crescenti), with the goal of easing the transition from fixed-term to open-ended contracts. ${ }^{4}$ More recently, pension reforms changed social security payments from being of the defined benefit type (with pensions calculated as a fraction of the last $3 / 5$ years of one's career) to being of the defined contribution type (where pensions depend on capitalized social security contributions over the entirety of one's career). Moreover, social security contributions in temporary jobs are smaller than in open ended contract to reduce the firm's labor costs.

Together, these reforms have created a de facto dual labor market, in which existing employees with open-ended contracts ("insiders") still enjoy a high degree of employment security and benefits protection, while many of the new hires ("outsiders") are offered temporary contracts with flexible wages and limited unemployment support. Naturally, the most affected by these changes are the cohorts who entered the labor market following the reforms.

Both women's and men's unemployment rates decline significantly during the first phase of labor market reforms. This is especially true for women's unemployment rate which fell from $11 \%$ in 1993 to $7 \%$ just before the great recession. However, most of the gains have been lost during the double-dip recession of 2008-2012, and unemployment rates in 2016 were $10 \%$ and $13 \%$, for men and women respectively. The large decline in unemployment rates of the 1993-2007 period has prompted several questions. The first is whether it represents just a statistical artifact coming from the emergence of previously a "shadow sector" or irregular employment. " Another issue is that the labor market reforms may have increased the size of the "gig economy", with many

\footnotetext{
${ }^{3}$ For simplicity, here and below we use the term "fixed-term contracts" to indicate all the various atypical contract forms introduced during this period. The main purpose of fixed-term contracts was to incentivize labor demand by reducing the firm's labor costs; it was also believed that such contracts would benefit workers by creating a faster "stepping stone" towards permanent employment. See Tealdi, 2011 for an exhaustive overview of the differences between fixed-term and open-ended contracts in terms of social security contributions, eligibility for unemployment insurance, severance pay, and various other aspects.

${ }^{4}$ This and more recent reforms implemented in 2018, aimed at partly moving away from a dual labor market model. Hence, they might contribute to undo some of the impact that previous reforms had on earnings inequality and volatility that we document in what follows. As our data end in 2016 we cannot empirically assess whether this is the case.

${ }^{5}$ Some statistics about the size of the shadow sector are provided by ISTAT. Each year ISTAT estimates the number of dependent and independent workers who work irregularly, i.e., with earnings that are not reported to the tax authority or the social security administration. In 1995 the "irregular" employment rate for dependent workers was $14.5 \%$; it fell to about $11.5 \%$ during the 2000 s (coincidentally with the first wave of labor market reforms), and it has been creeping back to around $13 \%$ in more recent years.
} 
effectively dependent workers being classified as self-employed workers due to the nature of the new labor contracts. This is an important issue since self-employed workers do not appear in the INPS registries that we have available. However, gig economy jobs are relatively recent and thus unlikely to explain the long-term trends.

\section{$2.2 \quad$ Data}

Our analyses are based on data from INPS (Istituto Nazionale di Previdenza Sociale), the equivalent of the US Social Security Administration. The data cover the period 1985-2016. We use a $6.6 \%$ sample of the Italian population based on 24 randomly selected birth dates. Public sector jobs, as well as self employment are not reported. These account for $16 \%$ and $20 \%$ of total employment respectively. ${ }^{6}$

The basic observation is a job relationship within a year, based on mandatory employer reports. Our main measure of earnings is the sum of all regular and irregular income (including bonuses, overtime work, etc.) across all jobs of a worker within a given year. For confidentiality reasons, the data are top-coded. The cutoff varies by year and is applied at the job level based on a daily maximum. According to our calculation it always exceeds the 99.5th percentile of the earnings distribution. ${ }^{7}$ In addition to earnings, the data include a broad measure of occupation (apprentice, blue collar, white collar, manager), industry, age, gender, location of the job, and whether the employment contract is fixed-term or open-ended (after 1998). Nominal values are first converted in euro (using the 2002 lira/euro exchange rate), and then deflated using the CPI to 2010 euros where applicable. All variables at the worker level that are specific to a job relationship such as the nature of the job and the cause of job separation, refer to the highest paying job, if more than one job record exists within the year.

A distinguishing feature of the data, compared to other featured in this volume, is the ability to observe labor supply on the extensive and intensive margins - the number of weeks worked at a job, the cause of separation, and whether the job is part- or full-time. We consider this information to be accurate since it is used to determine both social security contributions and benefits. Using this information, we impute the annual hours worked within the job. We assume that part-time jobs are 25 hours per week and full-time jobs are 40 per week, based on averages taken from the Italian SHIW (Survey of Household Income and Wealth). Then, we construct the annual hours worked as the sum across all jobs within a year, capped at 2,080 hours ( 38 hours $\times 52$ weeks). We obtain the average hourly earnings of each worker in each year as the ratio of the annual earnings to annual hours worked.

\footnotetext{
${ }^{6}$ Researchers interested in accessing the data can do so by submitting a formal request, accompanied by a research proposal, to INPS (see https://www.cliclavoro.gov.it/Barometro-Del-Lavoro/Pagine/Microdati-per-la-ricerca.aspx).

${ }^{7}$ The topcoding is applied by INPS at the employer/employee record level. Each record contains information on the number of (full time equivalent) days worked during the year (Days). Let $Y$ be actual earnings. In 2012, the INPS database reports: $Y^{*}=\min \{Y, 645 *$ Days $\}$. Since the maximum number of working days in a year is 312 , the topcode threshold in 2012 is approximately 200,000 euros. In other years the maximum is computed by adjusting the daily 645 euro threshold by an appropriate deflator (the "Indice delle retribuzioni contrattuali orarie lorde ISTAT", capturing the evolution of contractual retributions).
} 
For comparability with other countries in this special issue, we restrict our sample to workers aged 25 to 55 who have positive earnings and worked a minimum of 4 weeks over the year. We do not impose an additional minimum earnings threshold. Despite that, the first percentile of earnings in our sample never falls below 800 euros. The sample includes 2.3 million unique workers (1.4 million men and 0.9 million women) and a total of 22.4 million worker-year observations approximately 700,000 observations per year.

\subsection{INPS labor force trends and comparison with official statistics}

Figure 2 shows four relevant labor market trends as captured by the INPS dataset. First, the share of female workers increases from about $30 \%$ in 1985 to more than $40 \%$ in 2016. Second, the share of part-time workers also increases - from virtually $0 \%$ in 1985 to almost 30\% in 2016. Third, the share of workers working 52 weeks during the year decreases from approximately $88 \%$ in 1985 to $77 \%$ in 2016 (right hand side axis). Finally, the share of workers with an open-end contract (as opposed to a fixed-term contract) decreases from more than $90 \%$ in 1998 (the first year in which this information is collected) to $82 \%$ in 2016 (right hand side axis). This clearly paints the picture of a labor market transitioning away from one that is mostly representative of men employed all year round on a full-time basis.

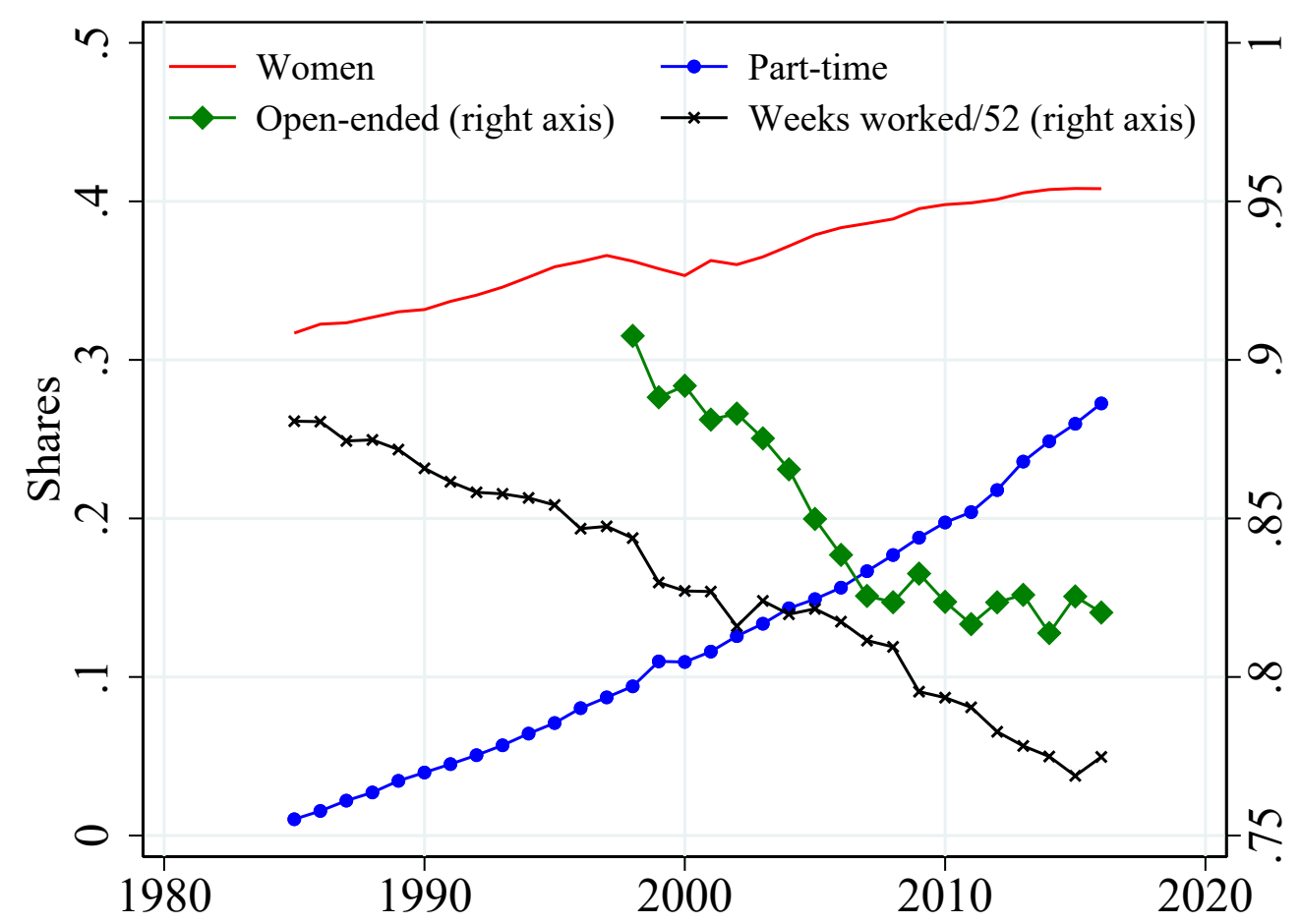

Figure 2: Labor market trends in the INPS dataset

These trends have affected the evolution of average earnings in recent years. In the Appendix (Figure A.6) we compare an index of earnings per unit of labor based on aggregate data (deflated by 
the CPI and normalized to 100 in 2015) with real average earnings from the INPS database (using only individuals aged 25 to 55). ${ }^{8}$ The two indices are far apart in 2000 and converge mechanically to 100 by 2015, but some of the differences reflect the fact that the ISTAT index is measured in units of labor. Two adjustments are needed for the INPS and ISTAT trends to be comparable. First, we need to account for the rise in part-time employment; second, we need to account for the decline in the fraction of workers working 52 weeks a year. ${ }^{9}$ As discussed above, these trends are large and hard to ignore. Not surprisingly, these two adjustments reduce the difference between the two series (we also experiment by multiplying the earnings of part-time workers by a factor of 1.5, 1.8 and 2, respectively, with minimal changes).

\section{Core statistics}

This section reports and analyzes statistics on the evolution of the distribution of earnings and earnings growth. We classify the analysis into three broad categories: inequality, volatility, and mobility.

\section{$3.1 \quad$ Inequality}

We start the analysis of inequality by looking at the evolution of the cross-sectional distribution of earnings. Figure 3, Panels (a) and (b), plots selected percentiles of the log earnings distribution relative to their 1985 values. The distribution of earnings goes through two distinct phases. Between 1985-1992 all percentiles rise, though percentiles above the median rise more. Between 1993-2016, all percentiles gradually decline, though this trend is much more pronounced for the bottom part of the distribution. ${ }^{10}$ The remaining panels document that these trends are similar for women (Panels (c) and (d)) and for men (Panels (e) and (f)). One notable exception is that for women median earnings declined as much as the 10th percentile in the second phase of the sample period, while for men median earnings have been much more stable.

These trends suggest that inequality is growing significantly. Figure 4, Panels (a) and (b), report the evolution of two direct measures of inequality, the P90-P10 gap and 2.56 times the standard deviation. The two measures are equal under normality. Hence, their difference can be

\footnotetext{
${ }^{8}$ The source for the aggregate data is ISTAT (the Italian Statistical Agency). We report the "indice delle retribuzioni lorde per ULA", from the ISTAT Oros survey. The Oros survey is aimed at producing quarterly indicators on gross wages, other labour costs and total labour cost for firms with at least one employee. Oros indicators are estimated by the integration of Social Security data (employers' social contribution declarations to INPS, the Italian Social Security Institution), and monthly Large firms Survey data (LES). The Oros target population are enterprises and private institutions with employees that, in the reference quarter, have paid wages and salaries subjected to social contribution obligations.

${ }^{9}$ Employment time has been shown to be a crucial determinant of earnings growth in Italy by Hoffmann and Malacrino (2019). Here we provide evidence that failing to account for the evolution in employment time could lead to misleading conclusions about the evolution of earnings levels too.

${ }^{10}$ The 1993 recession is likely a reason for this dramatic reversal. As documented in Miniaci and Weber (1999), this was the deepest recession since the end of WWII, with aggregate consumption, GDP, and disposable income falling in real terms by $2.5 \%, 1.2 \%$, and $5 \%$, respectively. The recession was characterized by widespread job losses, a the crisis of the traditional retail sector.
} 
used to get a simple gauge of deviation from normality. Both measures show a rising trend in earnings inequality. The measure based on the standard deviation is consistently higher, which suggests that the distribution has more pronounced tail features than the normal distribution. ${ }^{11}$ Panels (c) and (d) break the rising trends into top inequality, captured by the P90-P50 gap, and bottom inequality, captured by the P50-P10 gap. This decomposition reveals that while women and men have similar trends in overall inequality, their source is different. For women, most of the increase in inequality is coming from the top of the distribution, driven by a decline in median earnings, while for men there is an increase in top inequality between 1985-1992, then a rise in bottom inequality between 1992-2016.

\subsection{Top shares}

Concerns about rising inequality have recently sparked interest in statistics that focus on the earnings of workers at the very top of the income distribution (Atkinson et al., 2011). One common statistic is the share of income that goes to workers above a certain quantile of the distribution, such as the 99 th or 99.9 th percentile. The INPS data is top-coded above the 99.5th percentile. As a result, estimates of top income shares based on simple sums are mechanically biased downward, and non-parametric estimates of earnings quantiles above the 99.5 th percentile are not feasible. ${ }^{12}$ To correct for this bias we apply an adjustment to the top income shares based on the assumption that earnings above the top-code cutoff are Pareto distributed, with the same Pareto-tail index that governs the distribution just below the top-code cutoff.

There are several established methods for estimating the Pareto tail index, but those typically assume that the data are not top-coded. In Appendix A.2 we discuss four different methods for estimating the Pareto-tail index on top-coded data, and conduct a visual test showing that this assumption is a reasonable description of the data. The differences between methods are in their efficiency and robustness to outliers. Since in our sample the tail of the earnings data is distributed very close to Pareto, the different estimators end up producing economically similar estimates. For estimating top income shares, we choose the maximum likelihood estimator, which is theoretically the most efficient; we estimate the index using data between the 90th and 99th percentiles in each year. ${ }^{13}$ Our estimate of the Pareto tail index falls sharply between 1985-1992 (from 3.3 to 2.7) but since then has remained rather stable (in the 2.6-2.8 range, see Figure A.5 in the Appendix). This is considered a high Pareto tail index compared to those measured in other countries and that

\footnotetext{
${ }^{11}$ While INPS includes only private sector employees, trends for public employees are similar (see Figure A.7 in the Appendix, constructed using SHIW data).

${ }^{12}$ Another limitation of the INPS data is that they only include compensation benefits that are subject to social security contributions. For example, stock options became treated as ordinary income for tax purposes after 2008, but have remained exempt from social security contributions, and are thus excluded from the analysis. Since such benefits are more common among high earners, and are perceived to have risen in importance over time, the estimates of increase in top income share in this analysis may understate the top income inequality in Italy compared to, say, the US.

${ }^{13}$ By picking the 90th percentile as the lower threshold we make sure that there are enough observations making the estimate more robust to outliers. By picking the 99th percentile as the upper threshold we reduce the bias from observations that are partially top coded.
} 


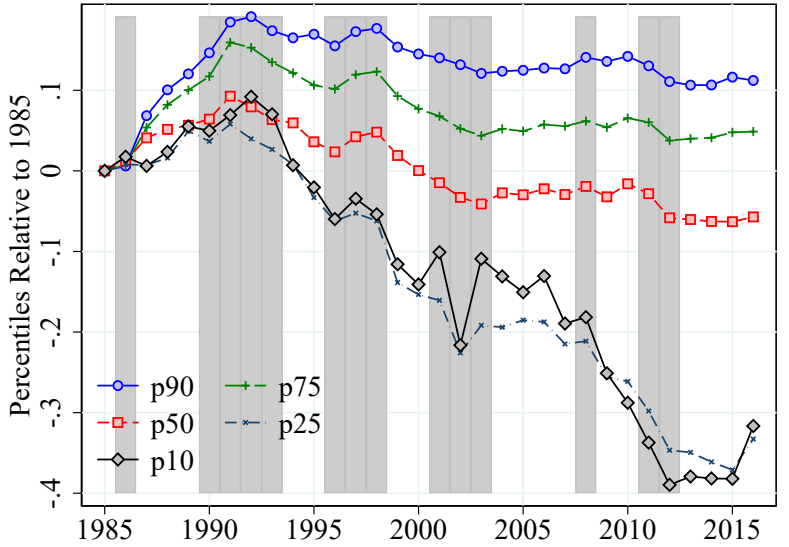

(a) All

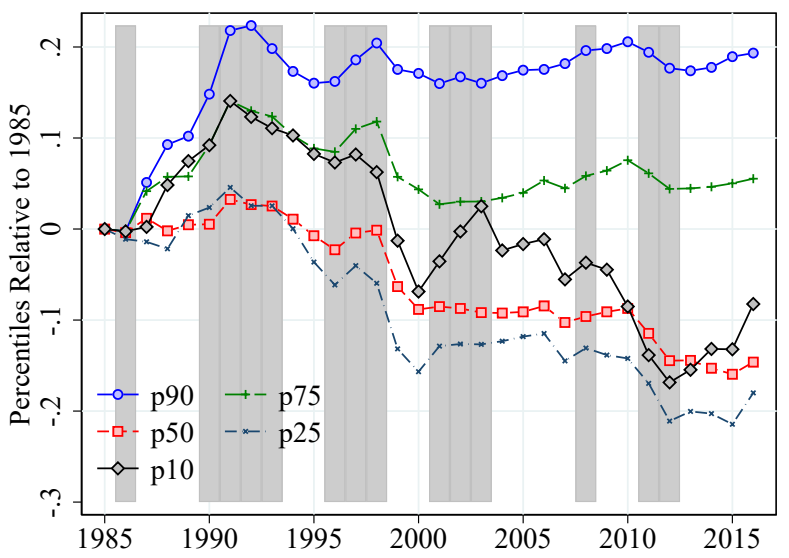

(c) Women

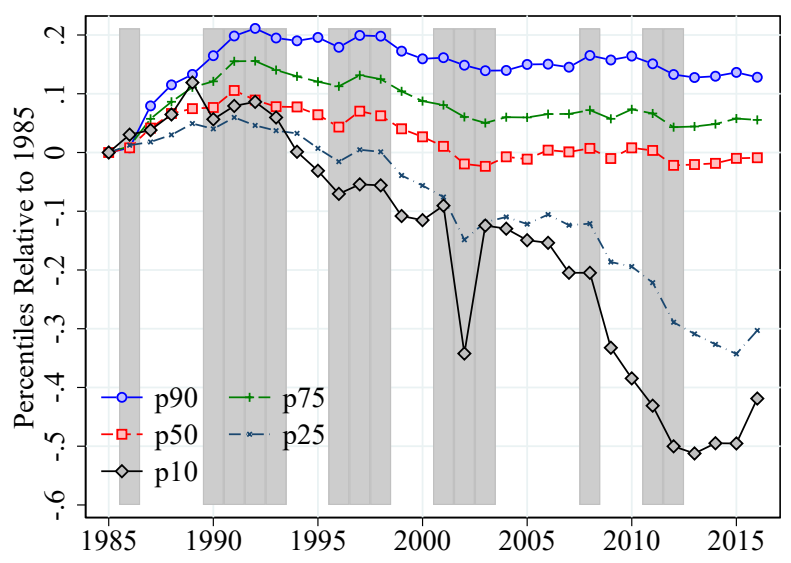

(e) Men

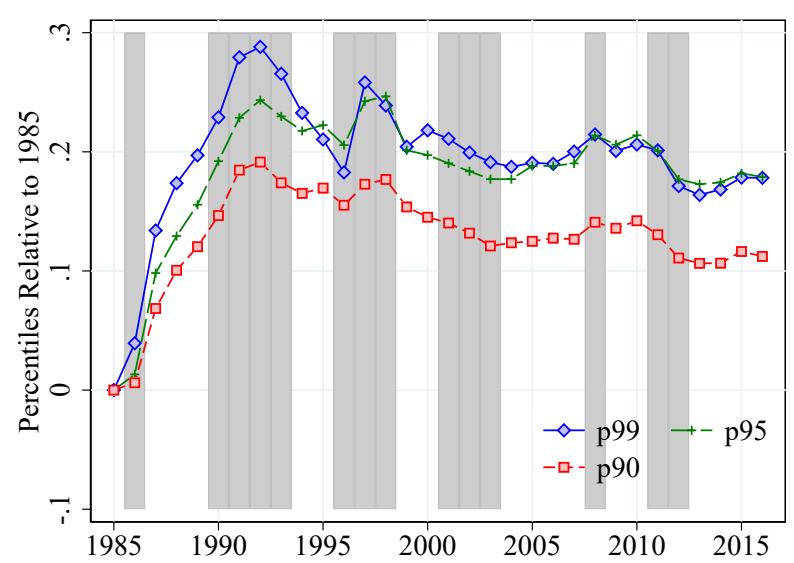

(b) All, top distribution

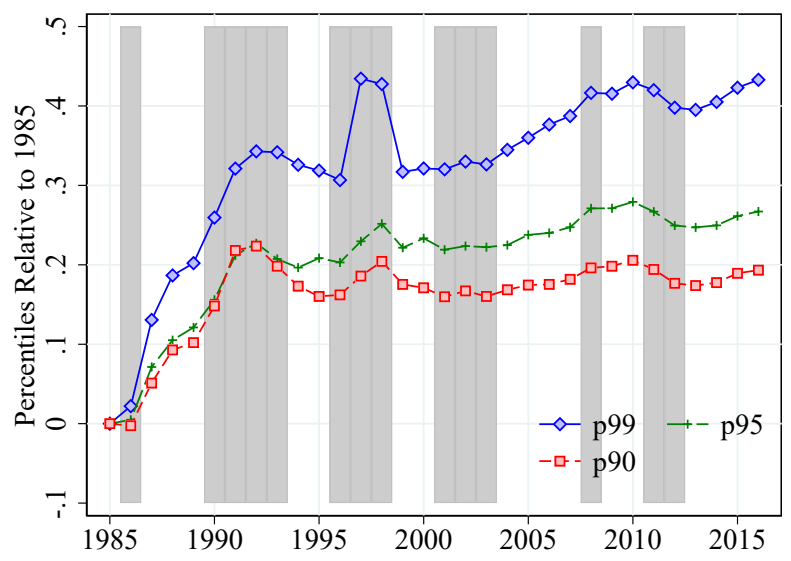

(d) Women, top distribution

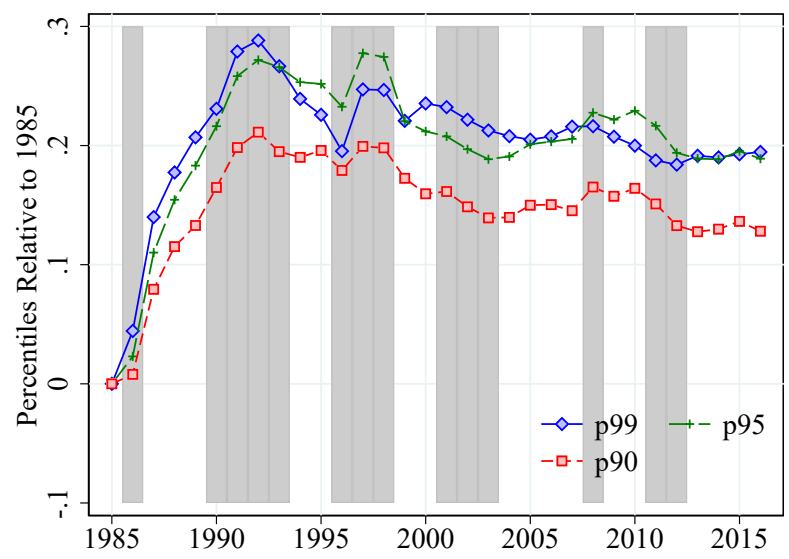

(f) Men, top distribution

Figure 3: Percentiles of the earnings distribution 


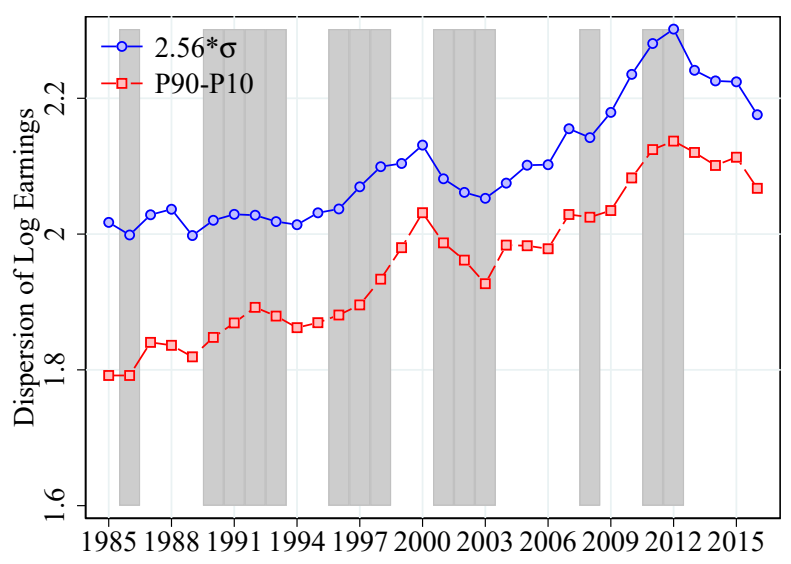

(a) overall inequality, female

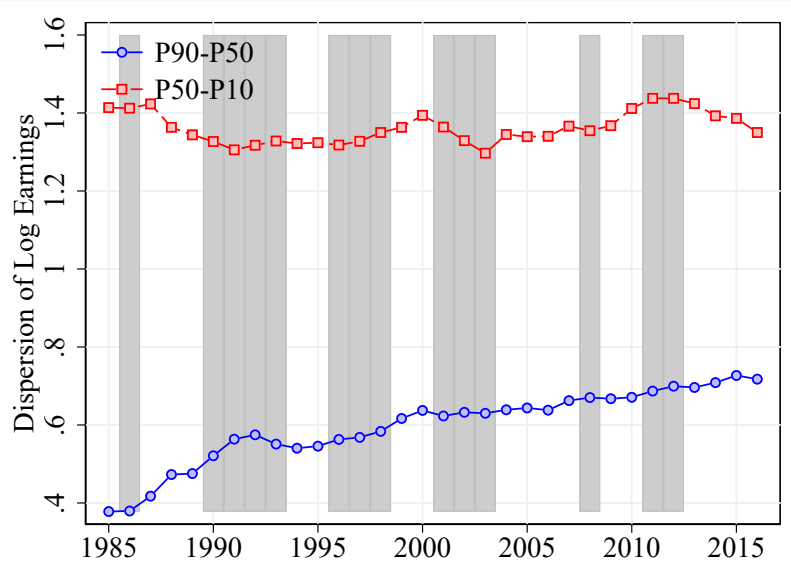

(c) top/bottom inequality, female

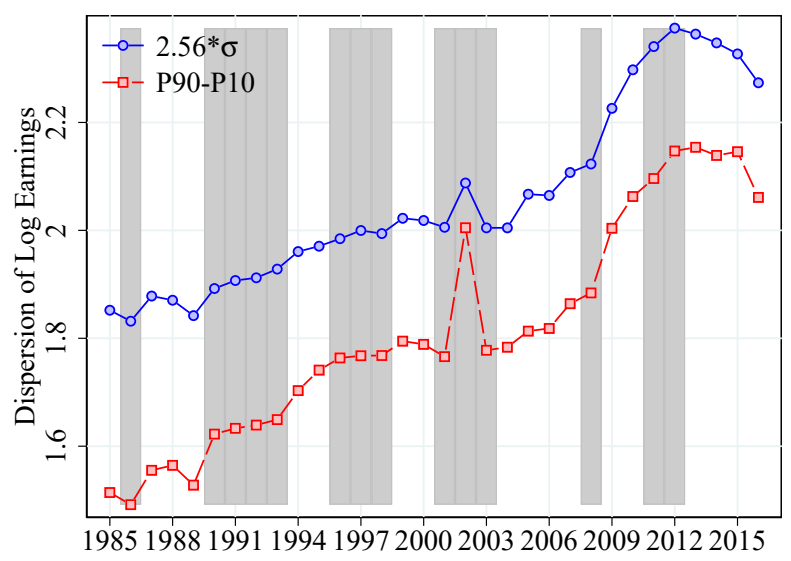

(b) overall inequality, male

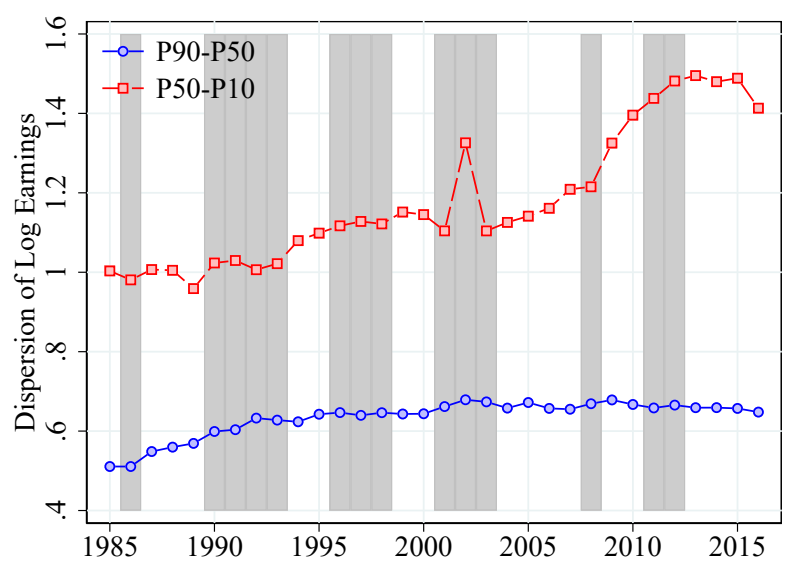

(d) top/bottom inequality, male

Figure 4: Inequality 

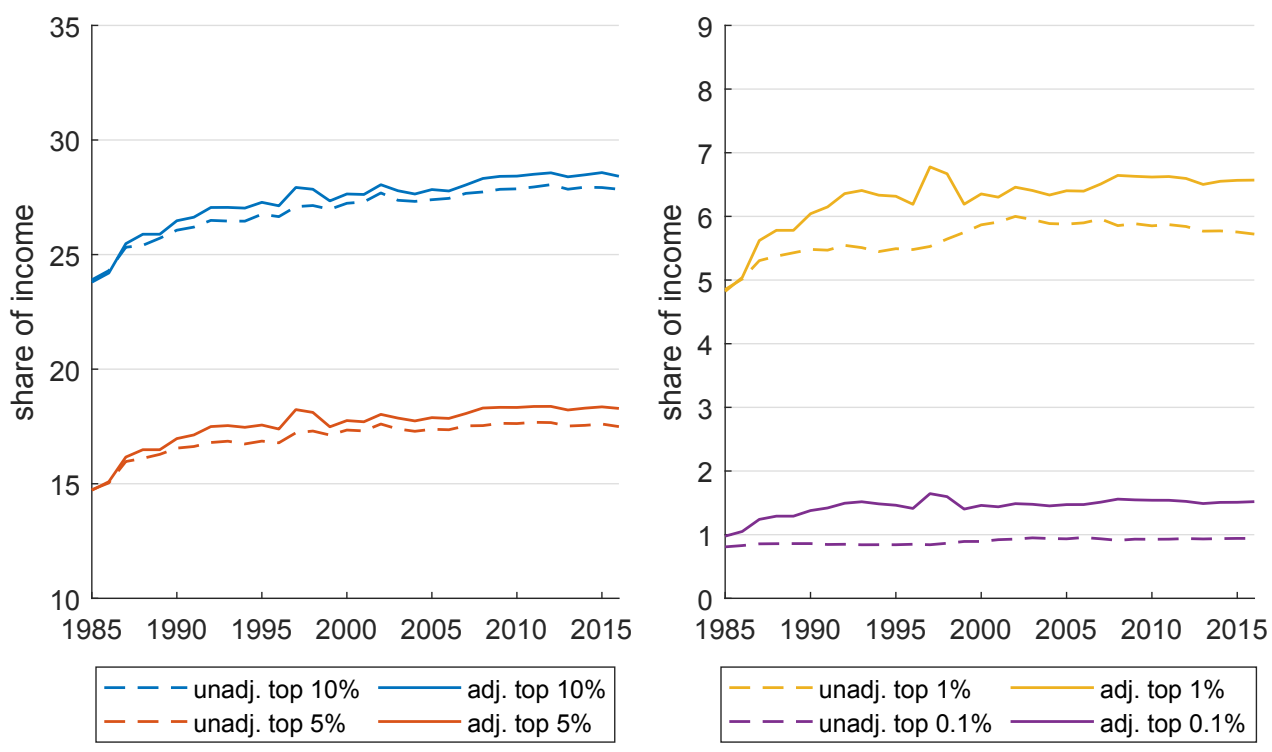

Figure 5: Adjusted and unadjusted estimates of top income shares

appear in this volume.

Figure 5 uses the estimates of the Pareto tail index to report the estimated 10\%, 5\%, 1\%, and $0.1 \%$ top income shares. The dashed lines represent shares calculated using simple sums of the top-coded data, while the solid lines represent the statistics adjusted for top-coding using the procedure outlined in Appendix A.2. Both the adjusted and unadjusted top income shares feature a relatively fast rise during the first five to ten years, and then very slow or no increase at all. The adjustment does not make much difference for the top $10 \%$ and $5 \%$ income shares, but it is crucial for documenting the rise in the top $1 \%$ and $0.1 \%$ income shares, which otherwise would be greatly underestimated.

\subsection{Inequality trends across cohorts}

There is much discussion in labor economics as to whether the level of inequality observed in a cohort of individuals depends on initial conditions as opposed to shocks that occur over the life cycle. Figure (6), Panels (a) and (b), plots the evolution of initial inequality (i.e., measured at age 25) for the cohorts entering the labor market between 1985 and 2016. We plot both the the P50-P10 gap (bottom inequality) as well as the P90-P50 gap (top inequality). For both men and women, initial bottom inequality is higher, and remains fairly similar over time, with a notable spike for the cohorts entering the labor market in the period surrounding the Great Recession. In contrast, initial top inequality has been on the rise since the late 1990's.

Panels (c) and (d) present the P90-P10 measure of inequality separately for selected birth cohorts (entering the labor market in 1985, 1995, 2005 and 2010) over the life cycle (the first point 


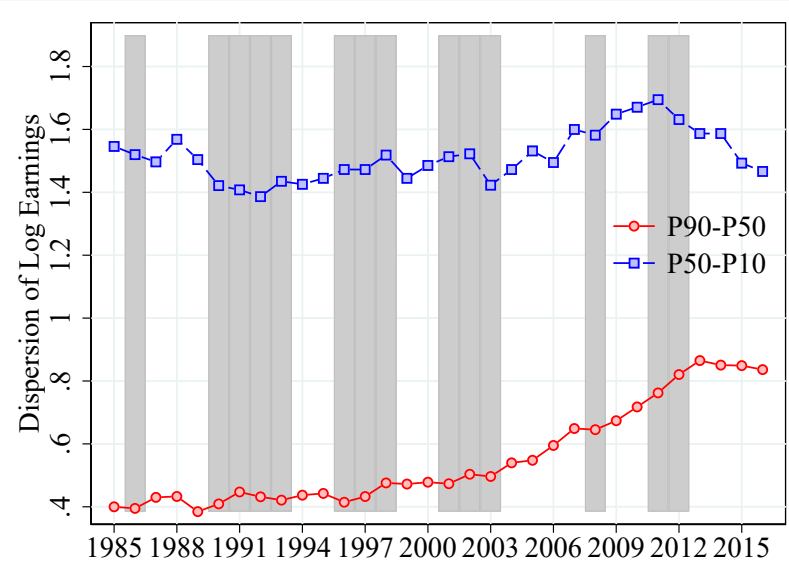

ri-

(a) Initial inequality - Women

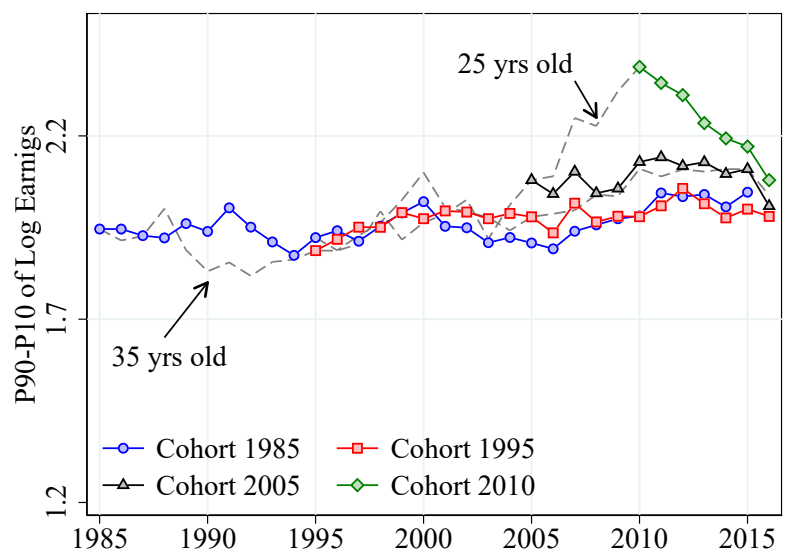

(c) Inequality by cohort - Women

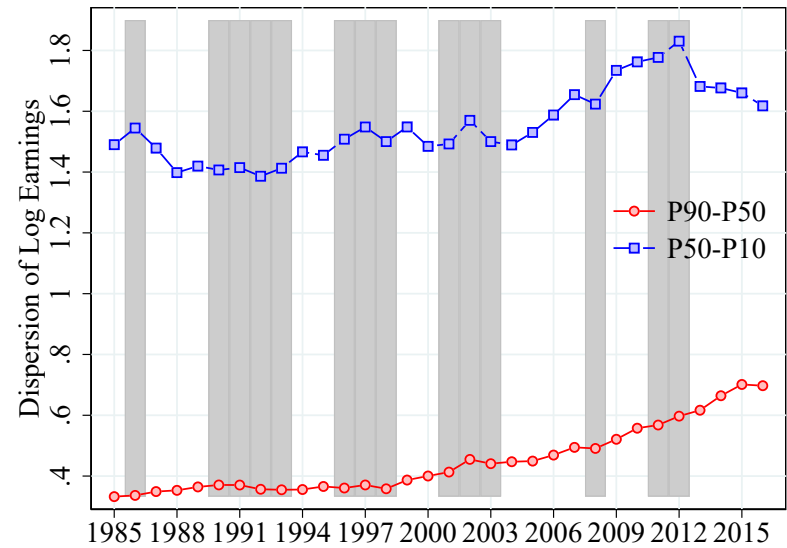

$\hat{i}^{-} \quad$ (b) Initial inequality - Men

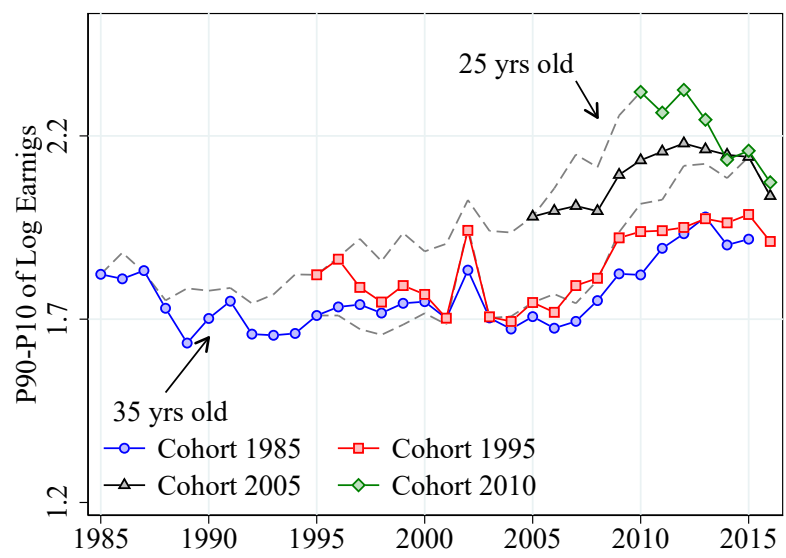

(d) Inequality by cohort - Men

Figure 6: Decompose inequality by cohort

on each line is always age 25). These panels reveal a stark pattern. For the cohorts that entered the labor market before 2000, inequality has been rather stable over the life cycle. For women in these cohorts inequality remained almost the same throughout the sample period; for men in these cohorts the level of inequality rises around the Great Recession and remains elevated since then. In contrast, cohorts that entered the labor market after 2000 faced rising initial inequality. However, cohort differences in the level of inequality decline as time goes by. The evidence thus suggests that entering cohorts after 2000 face a gradually changing labor market, which has relatively mild effects on older cohorts. We return to these trends and examine the role of structural labor market reforms in driving them below. 


\subsection{Volatility}

Measures of volatility, or the cross-sectional dispersion in earnings growth rates, are often interpreted as indicators of idiosyncratic labor earnings risk. In this section we explore the distribution of the one-year growth in residual earnings, denoted $g_{i t}^{1}$ and obtained after controlling for the age of the worker and the year. We describe volatility first using an overall measure (the P90-P10 percentile gap), and then break this down into the P90-P50 and P50-P10 percentile gap measures, which are direct indicators of "upside volatility" and "downside volatility", respectively.

Overall volatility, as measured by the P90-P10 percentile gap, is plotted in panels (a) and (b) of Figure 7, separately for women and men, respectively. Volatility increases significantly over the sample period. However, while for women the increase is concentrated in the first 15 years of the period, for men it lasts until the Great Recession, with both groups experiencing a slight decline thereafter. Note also that women face $50 \%$ more volatile earnings than men (likely reflecting more frequent entry and exit from the labor force), and the difference remains stable over time. The overall increase in volatility is consistent with the debate in Italian media and policy circles about the increased instability ("precariousness") experienced by workers.

Figure 7 decomposes overall volatility into upside and downside volatility, again separately for women and for men in Panels (c) and (d). Both volatility measures have a common trend that is increasing over time. As is documented elsewhere (Hoffmann and Malacrino, 2019), after taking out a time trend, the upside dispersion is procyclical and the downside dispersion countercyclical.

While economic risk is typically associated with measures of volatility, extreme tail events may also contribute to a worsening of the uncertainty faced by workers. Figure 8 shows more complex statistics that capture the asymmetry and central tendency of the distribution. Panel (a) shows the

Kelley skewness (defined as $\left.K=\frac{\left(P_{90}-P_{50}\right)-\left(P_{50}-P_{10}\right)}{P_{90}-P_{10}}\right)$, a measure of the degree of asymmetry in the distribution. If the distribution is symmetric, $K=0$; if there is more weight on the left tail (i.e., wage losses become more likely), $K>0$. The figure shows that Kelley skewness is almost always lower, in absolute terms, for women than for men. Given the procyclical nature of the upside volatility and the relative stability of the overall dispersion, the Kelley skewness is procyclical. Panel (b) shows the Crow-Siddiqui index (defined as $C S=\frac{P_{97.5}-P_{2.5}}{P_{75}-P_{25}}-2.91$ ), a measure of the "excess kurtosis" of the distribution. Any value above zero implies that the distribution has a stronger central tendency than the benchmark of the normal distribution.

Do younger cohorts face more instability ("precariousness") than older cohorts, as often argued in the popular press? Figure 9 shows the evolution of earnings volatility for selected cohorts as they age (with the dashed lines representing the level of volatility faced by the 25 year olds and 35 year olds in different calendar years). There are two basic takeaway points. The first is that volatility declines as people age (consistent with moves to more stable employment and wages). The second point is that the increase in volatility that happens over time partly reflects compositional changes, i.e., more recent cohorts facing higher levels of volatility than older cohorts. 


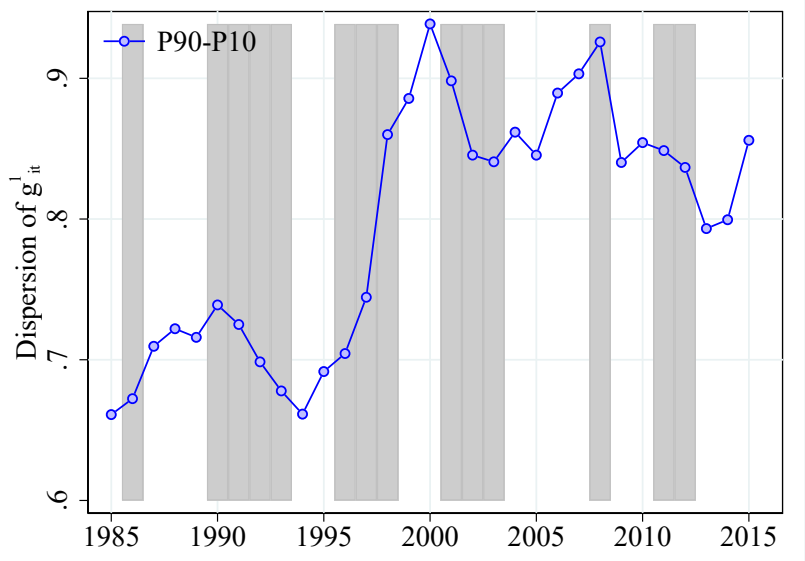

(a) Women

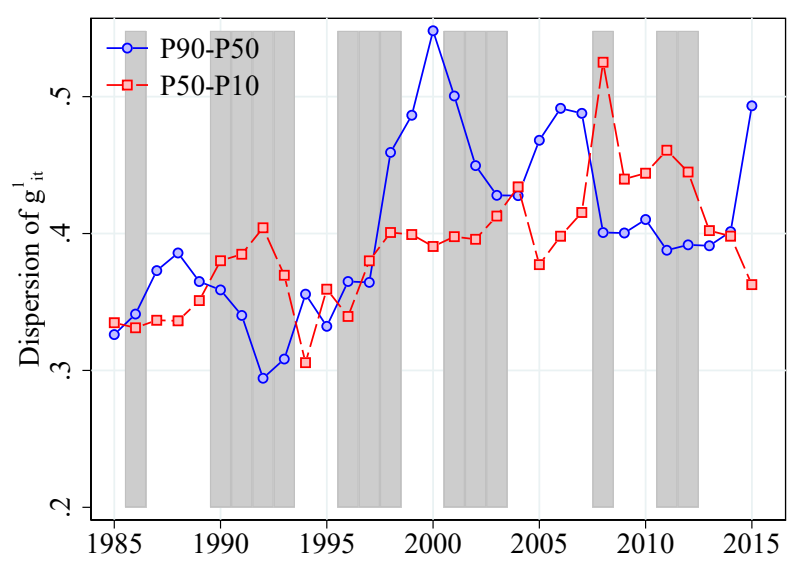

(c) Women

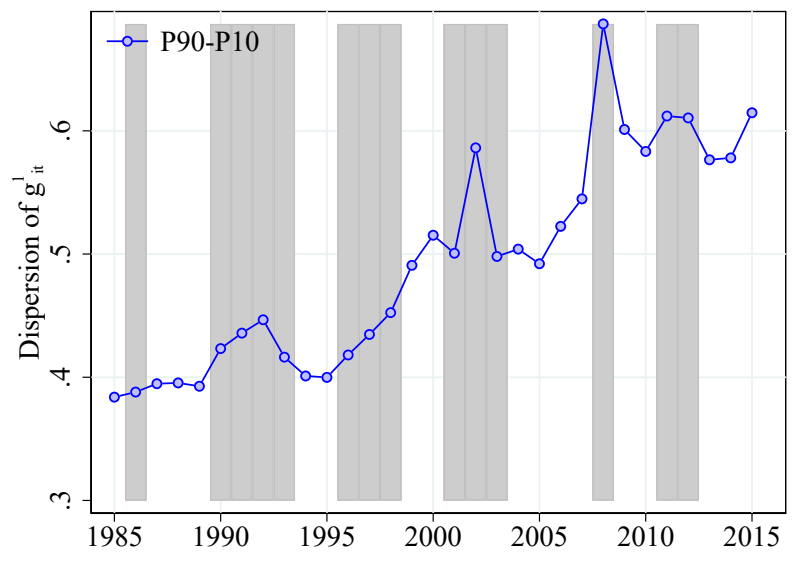

(b) Men

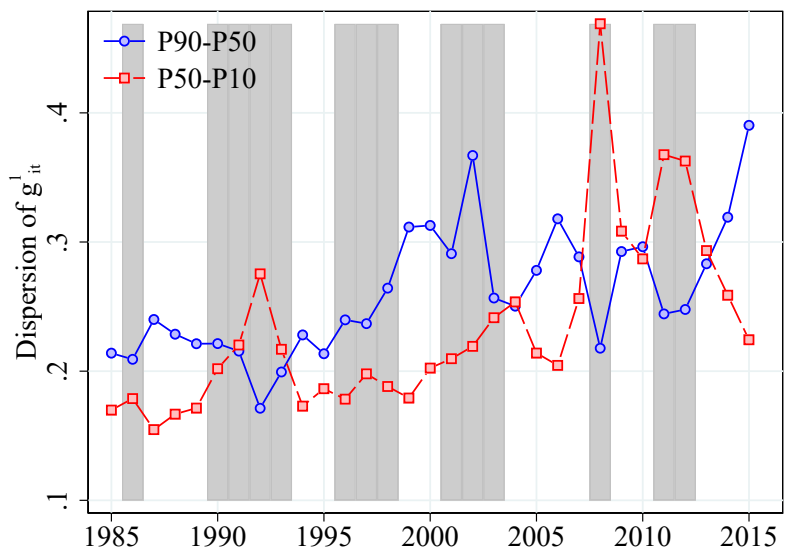

(d) Men

Figure 7: Volatility and its upside/downside decomposition

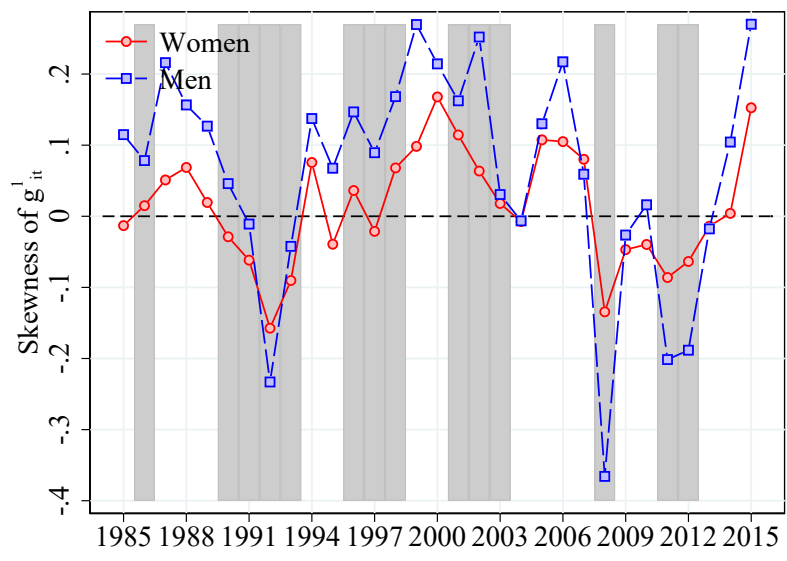

(a) Kelley Skewness

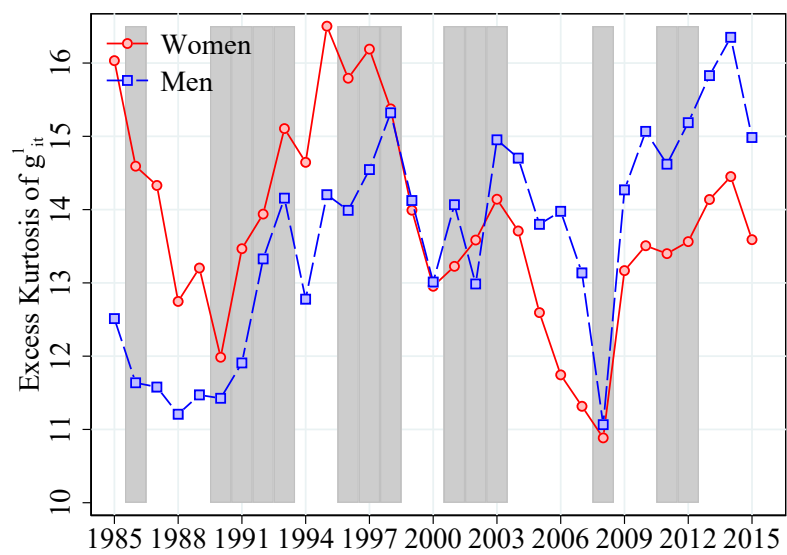

(b) Crow-Siddiqui Kurtosis

Figure 8: Asymmetrical and central tendencies of earnings growth 


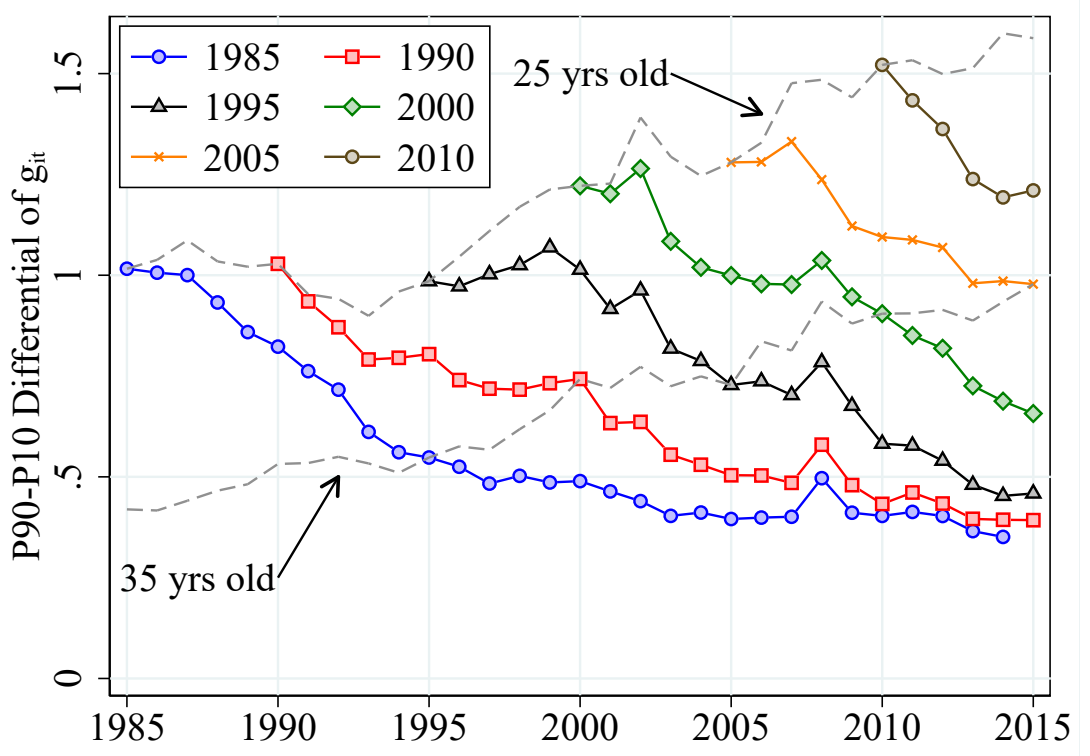

Figure 9: Volatility by cohort

\subsection{Heterogeneity in measures of volatility}

How does volatility affect different workers? Figure 10 reports measures of volatility, separately for women and for men, by permanent income percentiles. Permanent income is defined as average residualized log-earnings over the previous 3 years. The percentiles of permanent income are calculated using the distribution of permanent income in each sample year, then pooled together. Each line represents a different stage of the life-cycle (age 25-34, 35-44, and 45-55). As expected (and as remarked above), volatility declines as people age and move onto stabler jobs. For women, dispersion is concentrated in the early part of their career, most likely due to intermittent labor force participation. For men, dispersion is higher among low-permanent income workers.

Panels (c) and (d) plot the Kelley skewness coefficient by permanent income percentile; each line is again a different age group. There are now much starker differences between men and women. For men, the distribution appears rather symmetric in the middle of the distribution, and skewness is positive at the bottom and top of the distribution. Moreover, age effects are minimal. For older women the pattern is similar to men's. However, younger women face a degree of left skewness (a long left tail) that is steeply declining with permanent income percentiles, suggesting that women's earnings at the top the distribution revert significantly to the mean, a pattern that may be explained by more intermittent labor force participation during this stage of career for high-permanent income women (perhaps reflecting more generous maternity leave policies or employment protection).

The last two panels of Figure 10 plot the degree of excess kurtosis by permanent income percentiles, again separately for women and men. While the patterns are qualitatively similar (an inverted-U shape), there are stronger age effects and much higher leptokurtosis for women. ${ }^{14}$

\footnotetext{
${ }^{14}$ In the last two panel we do not plot the level of excess kurtosis for the top percentile of permanent income.
} 


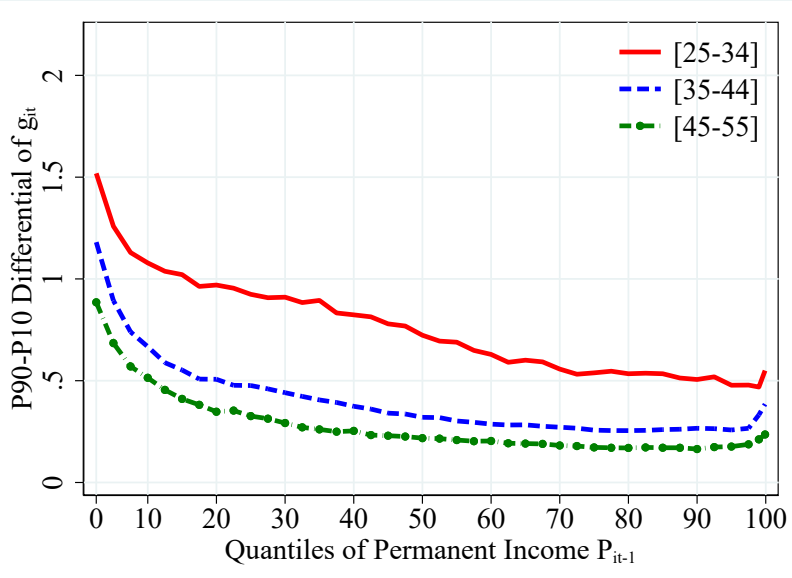

(a) dispersion, female

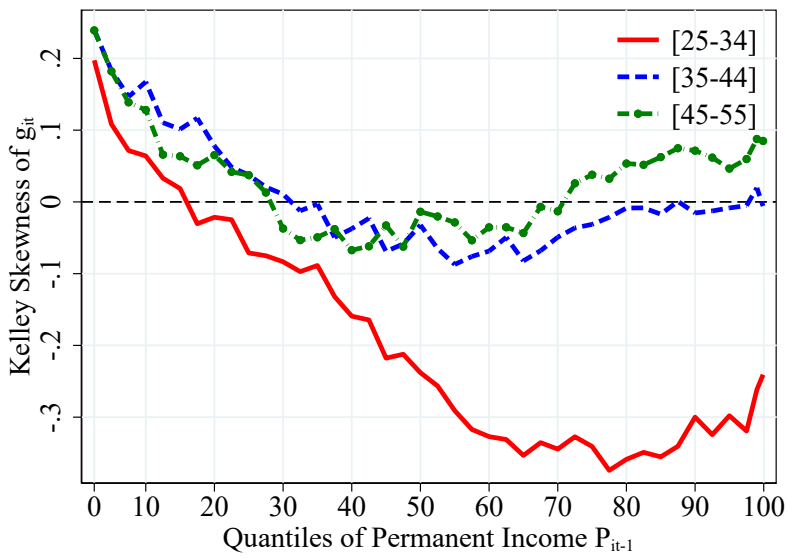

(c) skweness, female

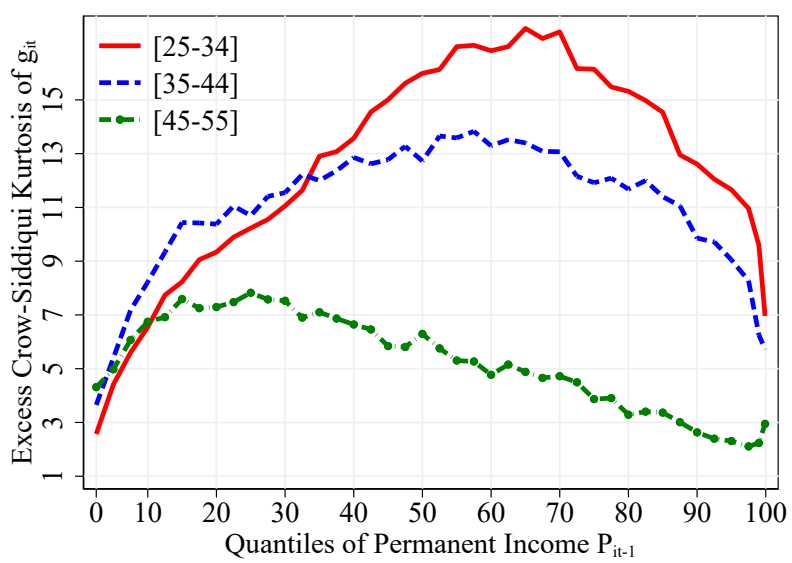

(e) Kurtosis, female

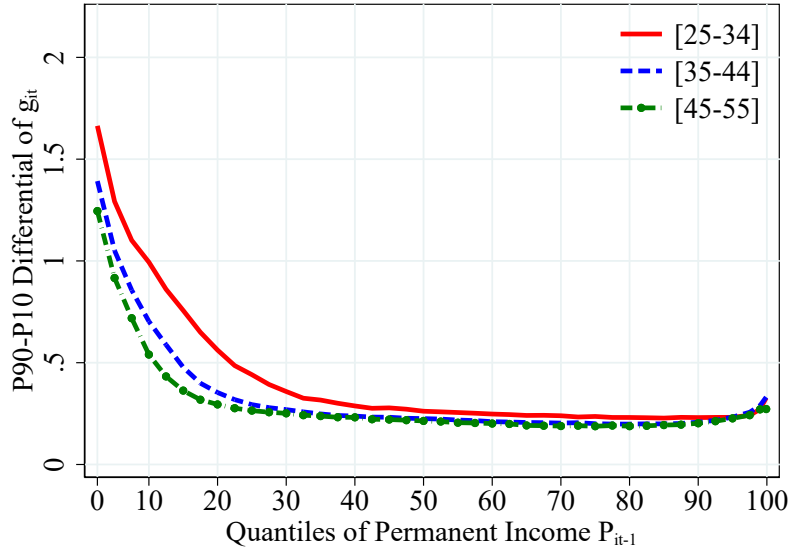

(b) dispersion, male

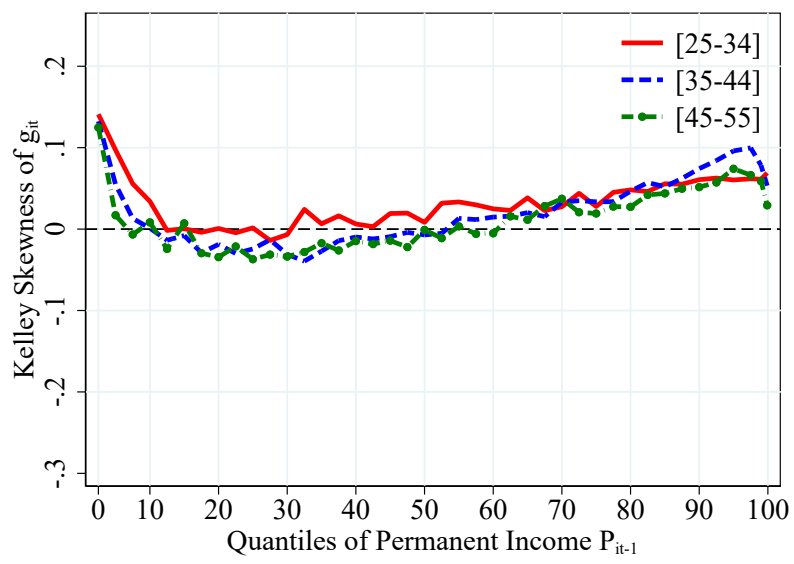

(d) skeweness, male

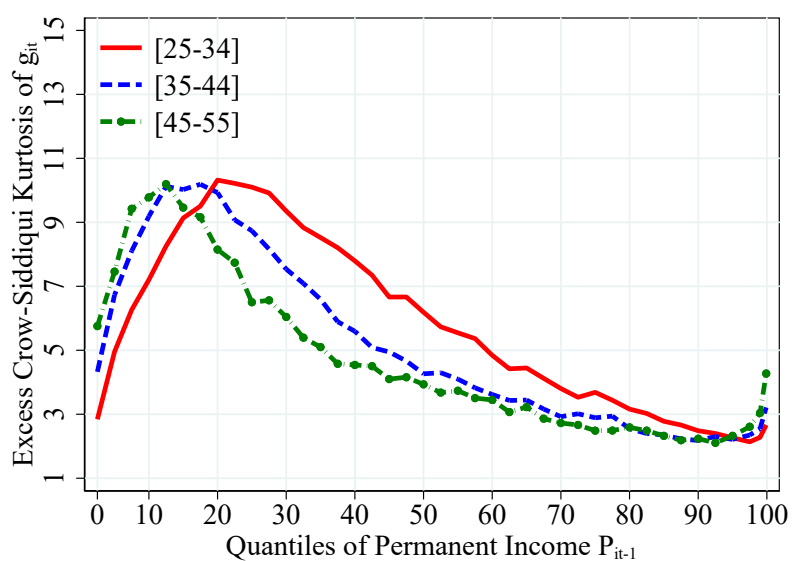

(f) Kurtosis, male

Figure 10: Volatility measures by income percentile 
Unlike Figure 10, Figure A.8 in the Appendix looks at the evolution of volatility over time rather than across stages of the life cycle. It shows that there are two distinct phases. From 1990 to 2000 volatility increases only for the bottom third of the permanent income distribution; between 2000-2010, all groups experience an increase in volatility except those in the top third of the distribution. Essentially, high-permanent income workers not only experience little increase in volatility between 1990 and 2010; they also face the least level of earnings volatility to start with. If volatility is really reflecting risk, this suggests that over time risk has shifted from people best equipped to insure against it to people least equipped to do so (assuming permanent income is a good measure of ability to self-insure).

\subsection{Mobility}

As opposed to volatility, which measures changes in total income over short periods of time, mobility refers to changes in the permanent component of income over extended periods of time. To evaluate mobility in the data, we first measure simple statistics to gauge the extent to which the current permanent income of workers is predictive of their permanent income in the future.

Figure 11 plots the average permanent income percentile in year $t+10$ conditional on the permanent income percentile occupied in year $t$. Panels (a) and (b) show these statistics separately for women and men, and separately for 25-34 year old and 35-44 year old. In a "perfectly mobile" distribution, in which past earnings are not predictive of future earnings, the mobility curve would be a flat horizontal line at the 50th percentile. In a "perfectly stagnant" distribution, in which workers stay in the same earnings percentile for their entire career, the mobility curve would coincide with the 45 degrees line, captured here by the black dashed line. The different age groups capture the life-cycle component of mobility. For both women and men, mobility is higher early in the career. This is especially true for low income workers that are expected to rise up to 20 percentage points in the permanent earnings distribution. At the top, there is mean reversion. Panels (c) and (d) show the same statistic for women and men in two different years, 1995 and 2005. The extent of mobility from different parts of the distribution does not change significantly over time.

While informative of trends across two specific years, these figures do not tell us immediately if overall mobility has declined or increased over the entire sample period. To do so, we construct a simple test. We first allocate workers to earnings percentiles; next, we regress the percentile they occupy in a given year against the percentile they occupy in the previous year (a rank-rank correlation analysis). The estimate of the rank-rank correlation coefficient is 0.89 (s.e. 0.0001), showing a rather low level of earnings mobility. As expected, long-term (four year apart) mobility increases slightly, but remains still quite low (a rank-rank correlation coefficient of 0.79 , with s.e.

In fact those individuals are disproportionately likely to have top coded earnings in two consecutive years implying that both the difference between P25 and P75 at the denominator of the formula for the Crow-Siddiqui index $\left(C S=\frac{P_{97.5}-P_{2.5}}{P_{75}-P_{25}}-2.91\right)$ is very close to zero along the sample, making the estimated kurtosis unplausible high. Notice that P2.5 is much less likely to be close to zero as extreme changes in income for those individuals are likely to come from large drops in earnings - implying these are probably workers who fell out of the top percentile after some consecutive years of high earnigs. Results including those data points are available from the authors upon request. 


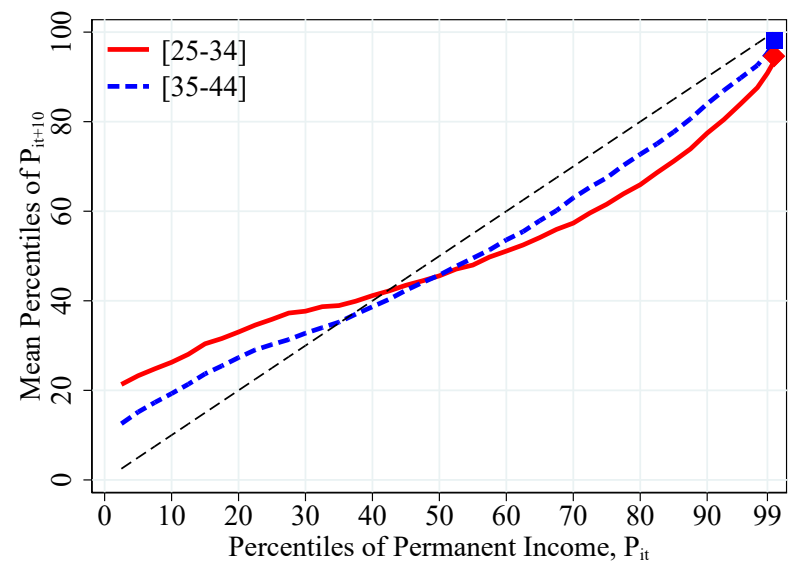

(a) Women, by age

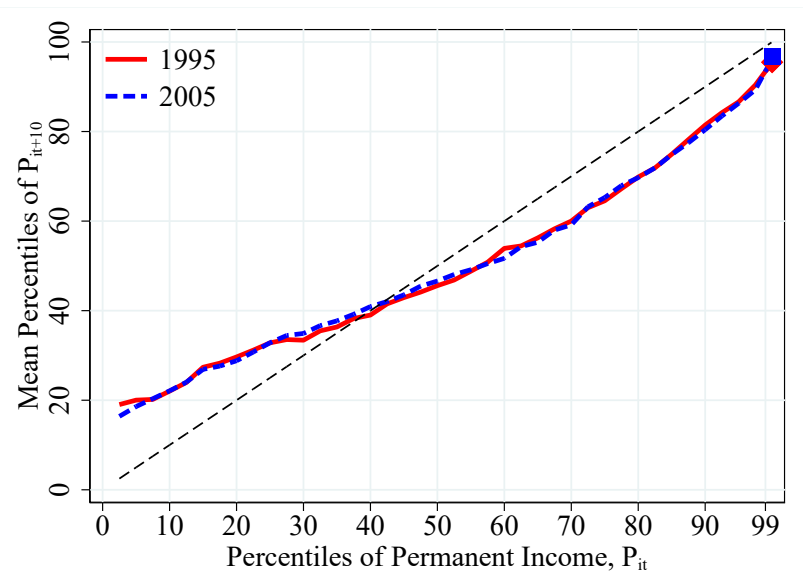

(c) Women, by year

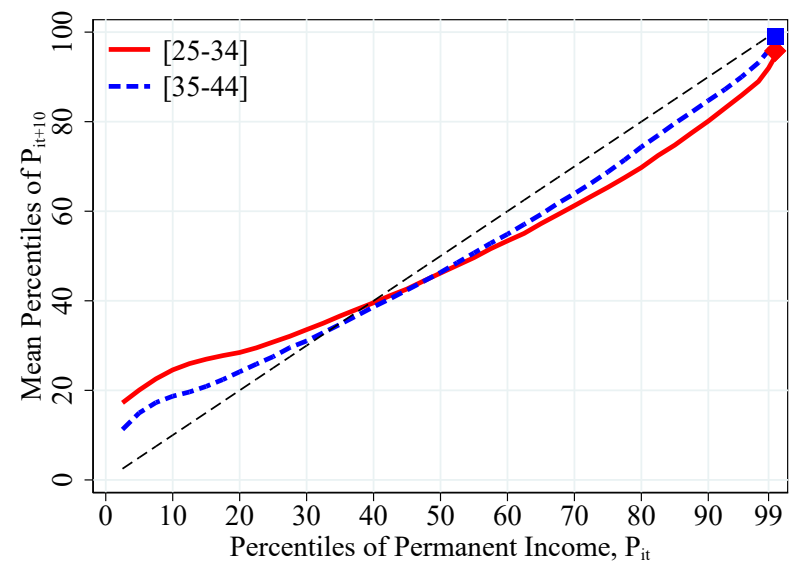

(b) Men, by age

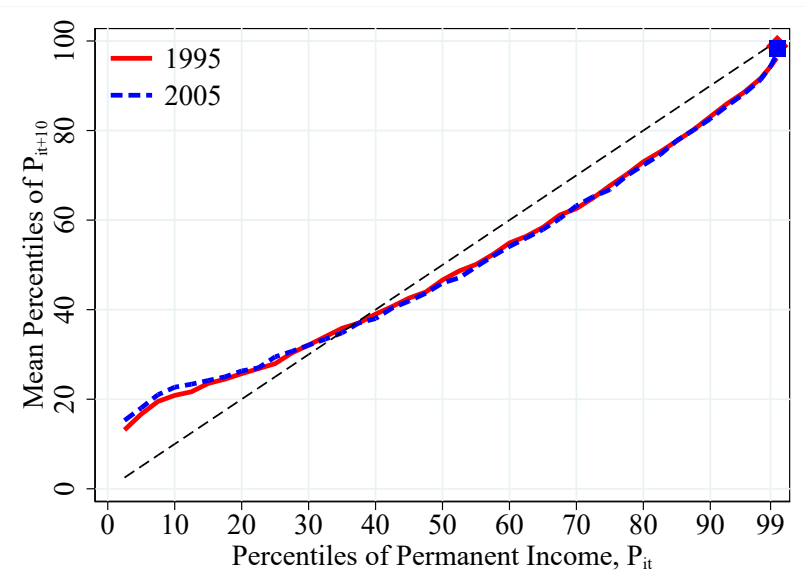

(d) Men, by year

Figure 11: Mobility 


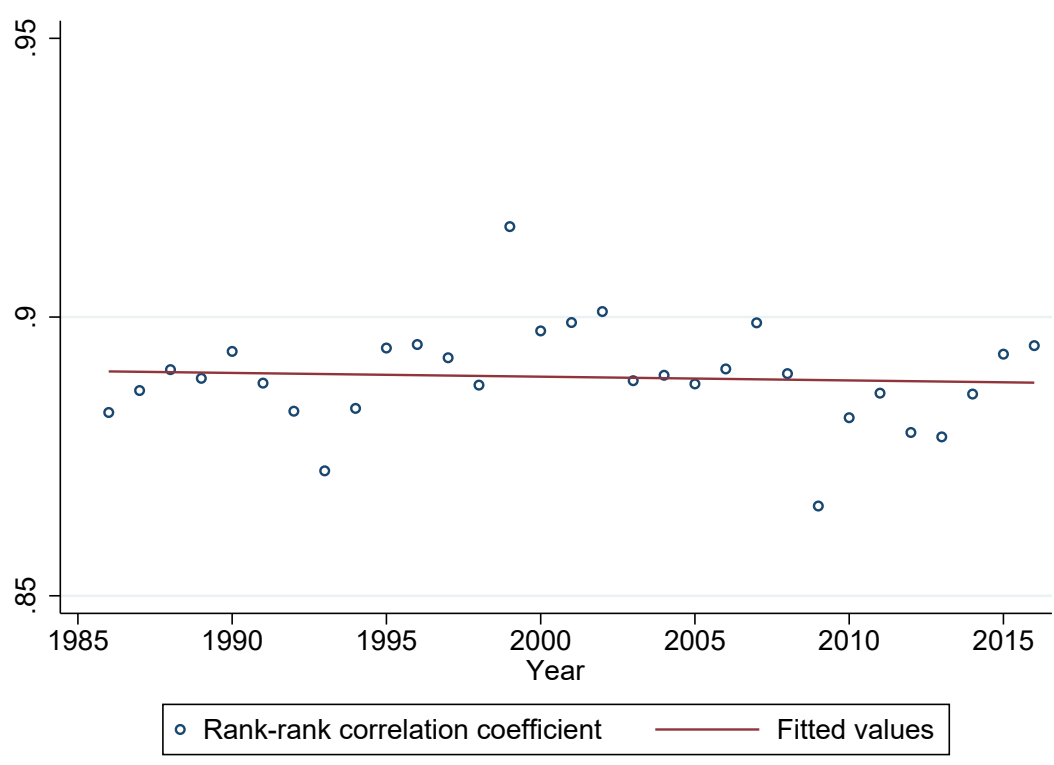

Figure 12: Mobility trends

0.0003). ${ }^{15}$ To test if this level has significantly changed over time, we add interactions with calendar year. The coefficient is very stable, ranging between 0.87 and 0.92 throughout (see Figure 12).

\section{What drives the trends?}

This section explores the immediate causes of the observed trends in inequality and volatility. To motivate the exploration, we start with a simple exercise that compares two sets of factors that may be responsible for long-run changes in the distribution of earnings. The first are dset comprises demographic factors, such as the rise in female labor participation and changes in the age composition of the labor force. The second includes changes in the nature of a job, such as the rise in part-time and fixed-term contracts. As discussed in Section 2, these trends were driven by a number of labor market reforms that, starting in the mid-1990s, made it easier for firms to offer atypical labor contracts. We evaluate the relative contribution of these factors by comparing the cross-sectional distribution of annual earnings in 2016 and two counterfactual distributions, which we construct using the procedure suggested by DiNardo, Fortin, and Lemieux (1996). The first fixes the age and gender composition of the sample to the 1985 baseline. This counterfactual distribution hence captures the effects of demographic factors. The second, besides fixing age and gender to the 1985 baseline, does so also for the part-time status of a job. It therefore captures the additional role of changes in the composition of jobs. ${ }^{16}$

\footnotetext{
${ }^{15}$ Mobility in our Italian sample appears lower than in the US. Using PSID data for the 1985-2012 period, and selecting for comparability a sample of employed workers aged 25-55, we find that the four-year apart rank-rank correlation coefficient is 0.74 (s.e. 0.0037) in the PSID sample.

${ }^{16}$ We do not condition on fixed-term contracts because they started being reported to INPS only in 1998 . An exercise using both part-time and fixed-term contracts with baseline composition in 1998 reveals a similar pattern.
} 

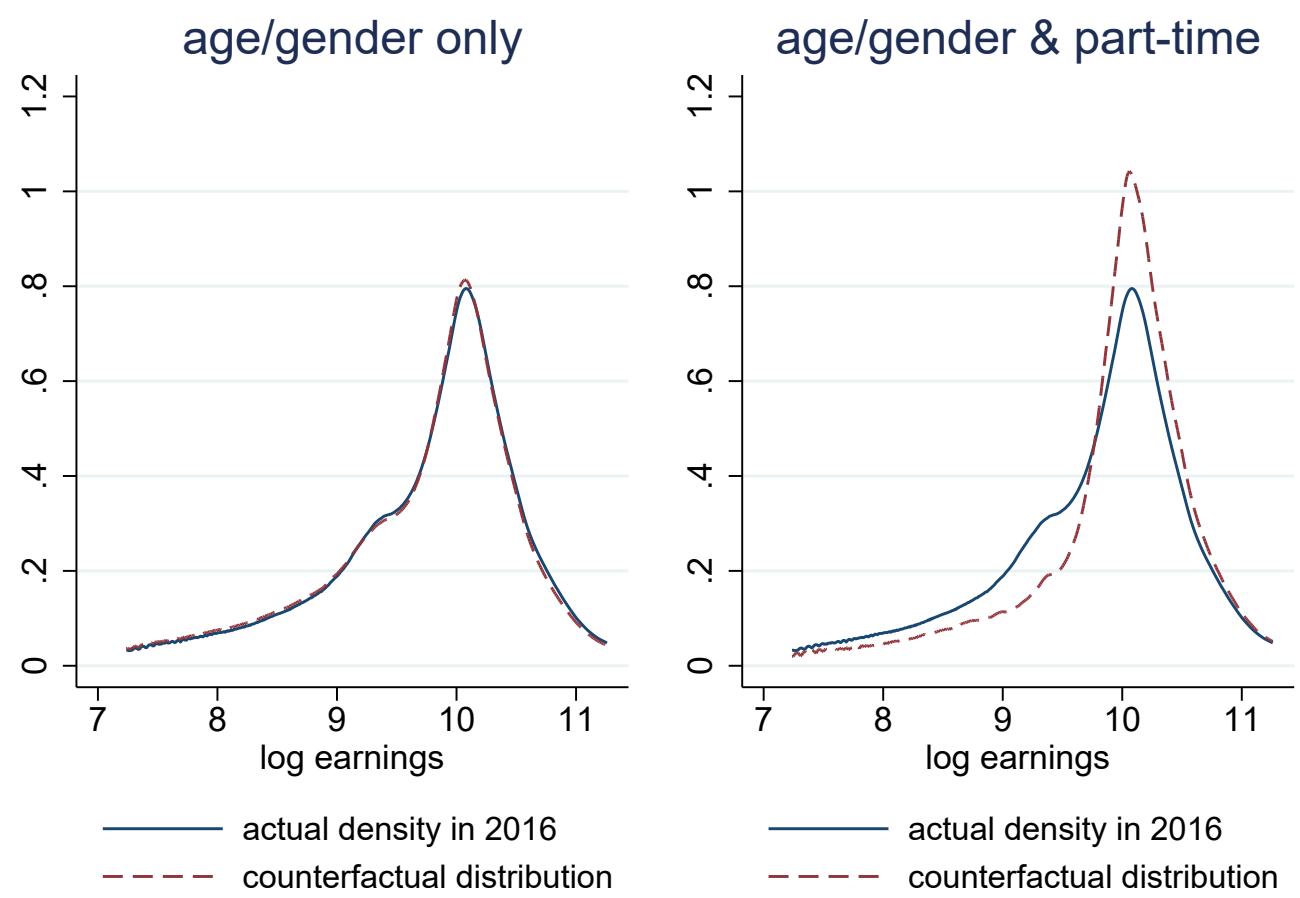

Figure 13: Counterfactual decomposition of earnings, demographic factors vs. job characteristics

Figure 13 shows the actual density of the cross-sectional earnings distribution in 2016 (the solid line) and the counterfactual density (the dashed line). In the left panel, the counterfactual distribution reweights observations to match the 1985 distribution of age and gender. Clearly, this counterfactual distribution overlaps almost entirely with the actual distribution. The right panel reweights observations to match the 1985 distribution of age, gender, and part-time status of a job. Since there were very few part-time jobs in 1985, this counterfactual is closely related to the distribution of earnings for workers with full-time jobs. This counterfactual is noticeably much different. It features a much thinner left tail, and is less dispersed around the mean. This exercise suggests that changes in the nature of jobs held by Italian workers are important drivers of the changes in the earnings distribution we discussed above, as opposed to demographic changes (increased female participation and population aging). In the analysis below we thus focus primarily on factors that determine the distribution of jobs.

We take advantage of three variables that are present in the INPS data (and typically unavailable in administrative social security data for other countries): weeks worked, contract type, and the cause of separation. Using these variables we answers four related questions. First, is the variation in annual hours worked or the variation in average hourly earnings that drive the observed trends in inequality and volatility? Second, is employment turnover induced by fixed-term contracts an important determinant of increased earnings volatility? Third, are fixed-term contracts a "stepping stone" for marginal workers entering the labor force, or do they represent merely a permanent shift 
towards jobs lacking traditional forms of employment protection? Fourth, did the dual labor market created by the reforms contribute to the stagnation in labor productivity?

\subsection{Decomposing annual earnings: Hours and wages}

We begin our exploration by following a familiar insight from labor economics: labor earnings are the product of the quantity of labor and the compensation per unit of labor. Here, we decompose earnings into annual hours worked and average hourly earnings in order to understand trends in earnings inequality and volatility.

In the INPS dataset we observe weeks worked and an indicator for part-time or full-time employment, but do not immediately observe actual hours worked. Annual weeks worked are reliable since they are used by the social security administration for establishing pension benefit eligibility. During our sample period they became even more important as pension reform used thresholds based on total years of social security contribution to determine who would be grandfathered under the older (and more generous) defined contribution system and who would be subjected to a mixed system or, for relatively recent labor market entrants, fall entirely under the new defined contribution system. To move from annual weeks worked to annual hours worked, we assume - as described in the Data section - that those working full-time do so for 40 hours a week, and those working part-time do so for 25 hours a week (averages we obtain from the SHIW, see Figure A.9 in the Appendix). We then construct annual hours as weeks worked times the assumed hours per week worked if employed part-time or full-time.

Let $y_{i t}, h_{i t}$ and $w_{i t}$ denote the logarithm of annual earnings, annual hours worked, and hourly earnings (mean compensation per hour worked), respectively. Then:

$$
y_{i t}=h_{i t}+w_{i t}
$$

This identity allows decomposing the variance of log earnings (a standard measure of inequality), into three components: the variance of hours, the variance of hourly earnings, and (twice) their covariance (a measure of labor supply elasticity):

$$
\sigma^{2}\left(y_{i t}\right)=\sigma^{2}\left(h_{i t}\right)+\sigma^{2}\left(w_{i t}\right)+2 \operatorname{Cov}\left(h_{i t}, w_{i t}\right) .
$$

Applying the same identity to the first difference, we can also decompose the variance of annual earnings growth $\Delta y_{i t}$ (a standard measure of volatility), into three components:

$$
\sigma^{2}\left(\Delta y_{i t}\right)=\sigma^{2}\left(\Delta h_{i t}\right)+\sigma^{2}\left(\Delta w_{i t}\right)+2 \operatorname{Cov}\left(\Delta h_{i t}, \Delta w_{i t}\right)
$$

Figure 14 applies these decompositions to each year in the sample. Panel (a) shows the decomposition of inequality (equation 2). In all years, the variance of hours is the dominant component of the variance of earnings. The cross-term is positive, which means that higher hourly pay is associated with greater labor supply. Both the component due to hours and the cross-term are rising 


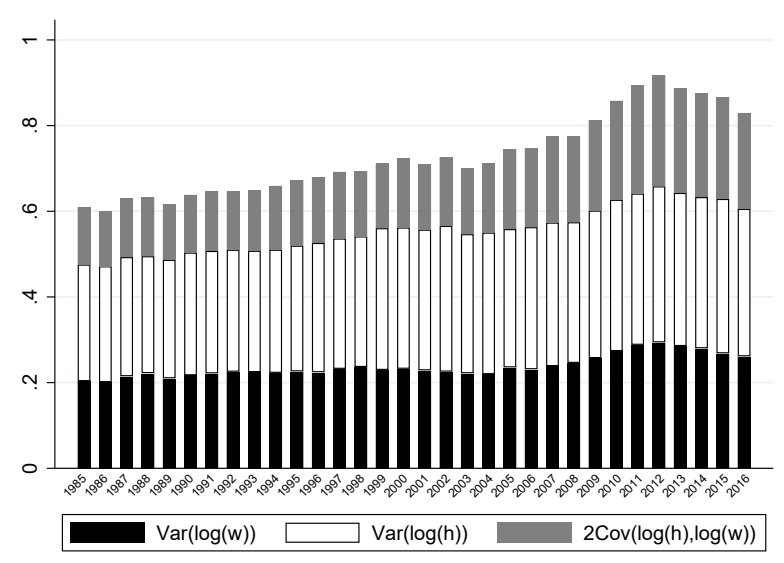

(a) inequality

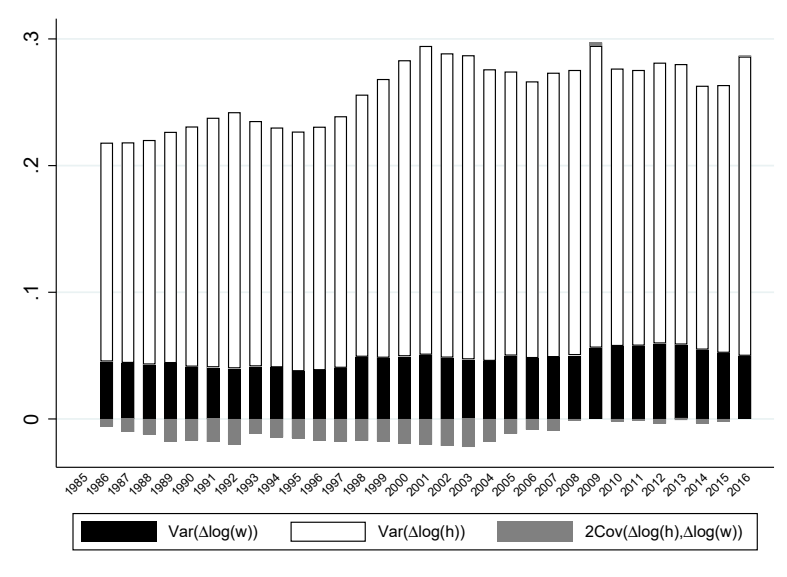

(b) volatility

Figure 14: Decomposition into hours worked and hourly earnings

over time. The hourly earnings component is stable for most of the sample period, except for a spike during the Great Recession. A simple accounting calculation shows that the variance of hours alone accounts for one-third of the rise in income inequality between 1985 and 2016; taking into account the cross term, this rises to $74 \%$. Panel (b) shows the decomposition of earnings volatility (equation 3). Once more, the dominant component is the variance of changes in annual hours. The cross term is relatively small and negative, suggesting that -net of heterogeneity in preferences for leisure- workers reduce their labor supply when their wage increases (i.e., that the wealth effect dominates the substitution effect). ${ }^{17}$

Hoffmann and Malacrino (2019) decompose annual earnings into annual weeks worked (instead of annual hours, as we do here) and weekly earnings. They show that labor supply is the dominant driver of the procyclical component of skewness. The mechanism is as follows. During recession, the separation rate increases and the hiring rate decreases. Due to the high separation rate, many workers experience a sharp fall in earnings. Due to the low hiring rate, these newly unemployed workers spend more time without a job, which increases the weight on the left tail of the distribution. During the recovery, the pool of non-employed workers is large, and their gradual hiring increases the weight on the right tail of the distribution. In comparison, the distribution of changes in weekly earnings is symmetric and does not vary much over the business cycle.

\subsection{Turnover and volatility}

What determines volatility in earnings? Some determinants of volatility are easy to trace: workers get promoted or demoted, switch employers, or change the quantity of labor on the intensive or the extensive margin. To quantify the contribution of these labor market events we construct a rolling

\footnotetext{
${ }^{17}$ Generally, measurement error in hours growth will generate a downward bias in the estimate of the covariance term, known as "division bias". Our measure of hours growth is based on administrative records of that are typically much more accurate, mitigating this bias to some extent.
} 
3-year worker-level volatility measure $\hat{\sigma}_{i t}^{2}$, defined as:

$$
\hat{\sigma}_{i t}^{2}=\frac{1}{3} \sum_{j=-1}^{1} \Delta y_{i t-j}^{2}-\left(\frac{1}{3} \sum_{j=-1}^{1} \Delta y_{i t-j}\right)^{2} .
$$

Then, we regress this worker-level volatility measure on labor market events that are observed in our data. Table 1, column (1), reports the results of a regression of $\hat{\sigma}_{i t}^{2}$ against indicators for separation from an employer by cause, as well as controls for age, gender, occupation, employers and sectors switching, part-time status, transitions from full- to part-time and vice versa, change in weeks worked, and dummies for time and region. In column (2) we also add worker fixed effects.

The key variables in these regressions are the separation indicators. They allow us to estimate how much earnings volatility changes in response to separations that can be classified as voluntary (quits), involuntary (layoffs), or predictable (a fixed-term contract ends). ${ }^{18}$ Focusing on the results in column (2) (our preferred specification since it also includes worker fixed effects), we find a a substantial role for unobserved worker heterogeneity, as reflected in the increase in the adjusted $R^{2}$ when fixed effects are included. In this specification, the contribution of end of contract and layoff are statistically indistinguishable (p-value 60\%). Since the average worker-level volatility among stayers is 0.10 , our results imply that a layoff or end-of-contract event would more than double individual earnings volatility relatively to the average volatility experienced by stayers. Note finally that our measure of worker-level volatility, $\hat{\sigma}_{i t}^{2}$, is only defined for people with positive earnings over three consecutive years. This may be a lower bound for the extent of earnings volatility experienced by those who exit the sample for one or more years following a separation. The fact that layoffs and ending of fixed-term contracts induce a similar rise in earnings volatility is surprising, since at least in principle layoffs are less anticipated than the end of a fixed-term contract. However, the evidence may be consistent with the fact that only a modest share of fixed-term contracts are converted into open-ended contracts when they expire (which suggests they are not unambiguous "stepping stones" to permanent employment). ${ }^{19}$

\subsection{Are fixed-term contracts stepping stones to permanent jobs?}

One of the cornerstones of the labor market reforms that began in the mid-1990s was the gradual removal of restrictions on firms' utilization of fixed-term contracts. As we report in the Section 2, the reforms were effective in that the share of fixed-term contracts rose from $8 \%$ of employment contracts in 1998 to $18 \%$ in 2016 . The analysis so far also points to a role of these new contract in the rising volatility of earnings. It is not surprising that this transformation of the Italian labor market has been controversial from the start.

\footnotetext{
${ }^{18}$ Figure A.10 in the Appendix shows how the share of separations by cause has evolved between 2005 and 2016 (unfortunately information on the cause of separation are missing before 2005), and highlights that the end of a fixed-term contract has become the most common cause of separation in recent years.

${ }^{19}$ Of the workers who are on a fixed-term contract in year $t, 63 \%$ continue to work with the same type of contract at time $t+1$ (44\% with the same employer, $19 \%$ with a different one); $19 \%$ transition to an open-ended contract ( $10 \%$ with the same employer, $9 \%$ with a different one); and $17 \%$ leave employment altogether.
} 
Table 1: Volatility

\begin{tabular}{|c|c|c|}
\hline & $(1)$ & $(2)$ \\
\hline \multirow[t]{2}{*}{ Cause Separation: Layoff } & 0.267 & 0.135 \\
\hline & $(0.002)$ & $(0.002)$ \\
\hline \multirow[t]{2}{*}{ Cause Separation: Quit } & 0.169 & 0.073 \\
\hline & $(0.002)$ & $(0.002)$ \\
\hline \multirow[t]{2}{*}{ Cause Separation: End Contract } & 0.202 & 0.133 \\
\hline & $(0.002)$ & $(0.002)$ \\
\hline \multirow{2}{*}{ Cause Separation: Other } & 0.171 & 0.093 \\
\hline & $(0.004)$ & $(0.004)$ \\
\hline \multirow[t]{2}{*}{ Age } & -0.015 & -0.003 \\
\hline & $(0.000)$ & $(0.001)$ \\
\hline \multirow[t]{2}{*}{ Age squared /100 } & 0.013 & 0.009 \\
\hline & $(0.000)$ & $(0.001)$ \\
\hline \multirow[t]{2}{*}{ Female } & 0.052 & \\
\hline & $(0.001)$ & \\
\hline \multirow{2}{*}{ Occ: Blue collar } & -0.050 & 0.027 \\
\hline & $(0.004)$ & $(0.007)$ \\
\hline \multirow[t]{2}{*}{ Occ: White collar } & -0.086 & -0.004 \\
\hline & $(0.004)$ & $(0.006)$ \\
\hline \multirow[t]{2}{*}{ Occ: Middle manager } & -0.103 & -0.015 \\
\hline & $(0.004)$ & $(0.007)$ \\
\hline \multirow[t]{2}{*}{ Occ: Executive manager } & -0.081 & -0.028 \\
\hline & $(0.005)$ & $(0.008)$ \\
\hline \multirow[t]{2}{*}{ Main job was part-time } & -0.009 & -0.053 \\
\hline & $(0.001)$ & $(0.002)$ \\
\hline \multirow[t]{2}{*}{ Full time to part time } & 0.234 & 0.168 \\
\hline & $(0.003)$ & $(0.003)$ \\
\hline \multirow[t]{2}{*}{ Part time to full time } & 0.153 & 0.054 \\
\hline & $(0.003)$ & $(0.003)$ \\
\hline \multirow[t]{2}{*}{ Job switcher } & 0.119 & 0.060 \\
\hline & $(0.001)$ & $(0.001)$ \\
\hline \multirow[t]{2}{*}{ Sector switcher } & 0.095 & 0.057 \\
\hline & $(0.002)$ & $(0.001)$ \\
\hline \multirow[t]{2}{*}{ Change in weeks worked/52 } & -0.017 & -0.009 \\
\hline & $(0.002)$ & $(0.002)$ \\
\hline Individual fixed effects & NO & YES \\
\hline Adj. R2 & 0.084 & 0.449 \\
\hline Observations & $5,789,700$ & $5,836,552$ \\
\hline Mean volatility stayers & 0.097 & 0.097 \\
\hline P-value Layoff=End-contract & 0.000 & 0.602 \\
\hline
\end{tabular}

Notes: This table reports the coefficients from regressing a rolling measure of annual earnings volatility (see main text) on causes of job separation and other controls. The omitted category among the causes of separation is a dummy that takes value one if the worker did not experience a separation in year $t$. The omitted category among occupations is a dummy for apprenticeship. All specifications include year, region, and firm size dummies. The last column includes individual fixed effects. Standard errors are clustered at the worker level. 
The standard argument in favor of allowing fixed-term contracts with little to no employment protection (while preserving strong employment protection for employees in traditional open-ended contracts), is that firms facing uncertainty are reluctant to hire workers on a permanent basis if laying them off at a later date involves large costs. Allowing firms to hire workers on a temporary basis may increase job creation and efficiency, discourage informal work, and draw more workers into the labor force. Those new workers, who would otherwise have remained out of the labor force, find gainful employment and form relationships that may lead them to permanent jobs later on. Following Booth, Francesconi, and Frank (2002), we call the idea at the basis of this argument the "stepping stone" hypothesis. The standard counterargument is that the introduction of fixedterm contracts creates a two-tiered labor market, in which "insiders" with open-ended contract enjoy high incomes with stability and generous pension benefits, while "outsiders" are forced to take fixed-term contracts without any of those protections, and without a realistic chance of ever becoming insiders. As a consequence, some workers, mostly unskilled and in cohorts that enter after the reforms, are permanently shifted towards jobs lacking traditional forms of employment protection. ${ }^{20}$

In this subsection we shed light on these hypotheses in three ways. First, we document large differences in the incidence of fixed-term contracts across worker birth cohorts. The left panel of Figure 15 shows that workers who entered the labor market after the reforms are much more likely to be employed with such contracts. Specifically, in 2016 more than one-third of workers who entered the labor market in that year held fixed-term contacts, as opposed to $20 \%$ among those who entered the labor market a decade earlier, and $15 \%$ among those who entered the labor market two decades earlier. While there is some convergence across cohorts in the share working on fixed-term contracts, it is far from rapid; this has important consequences for human capital accumulation patterns, as we shall see below.

Second, we document equivalently large differences in worker entry and exit rates from the labor market. The right panel of Figure 15 reports the share of intermittent workers by cohort. We define an intermittent worker as one who is employed in year $t$, but has no record of employment in either year $t-1$ or $t+1$. The cohorts entering the labor market after the labor market reforms have a larger share of intermittent workers.

Finally, one argument in favor of fixed-term contracts is that they allow workers to enter the labor market earlier than they would have done otherwise, and this may help them improve the chances of securing a permanent open-ended contract at a later date. We test this idea informally in Table 2, where we consider two different samples. In sample 1 the "early starters" are individuals who were employed at age 25 with a fixed-term contract, while the rest of the sample is people who were unemployed at age $25 .^{21}$ In sample 2 we add the condition that both are employed at age 26. These two samples capture, in different ways, the idea that the "early starters" had an advantage

\footnotetext{
${ }^{20}$ See Boeri and Garibaldi, 2007 for a discussion of the effects of fixed-term contracts on mean employment and on aggregate fluctuations in employment. They argue that the introduction of fixed-term contracts leads to a "honeymoon period" in which employment and output increase, but labor productivity decreases.

${ }^{21}$ Strictly speaking, they were out-of-sample, not necessarily unemployed.
} 

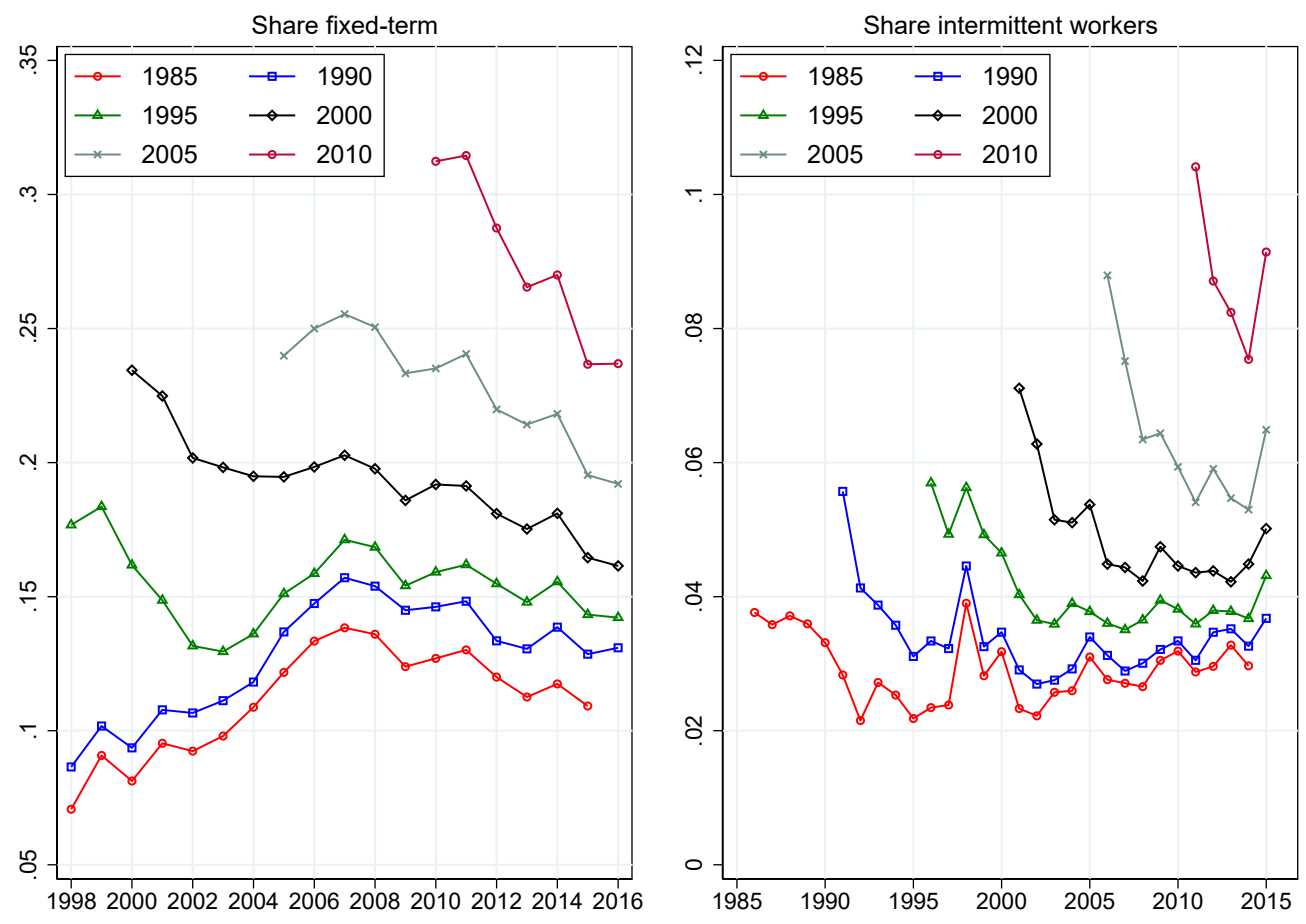

Figure 15: Shares on fixed-term contracts and intermittent workers, by cohort

in terms of an early entry in the labor market through a fixed-term contract and, the argument goes, should get a faster transition than those who delay their entry into an open-ended contract. In all cases, the dependent variable is whether the worker is on an open-ended contract (between age 27 and 35).

For each sample, we present two specifications. One looks at the unconditional probability of holding an open-ended contract. In all cases, it appears that an early start confers a slight to decent advantage to hold a permanent contract job. However, there are several compositional issues to be concerned about: those who start earlier may be of lower quality or face more predictable labor market interruptions. In the second specification, we control for average log-income during the first decade in the labor market (which implicitly conditions on employment), gender, age, and the employment status at age 26 (with being out-of-sample being the excluded category in sample 1). Clearly, an early start through a fixed-term contract no longer confers any significant advantage in terms of securing permanent employment for most of the early stage of one's career, and if anything the early starters (conditioning on characteristics) have a slightly lower probability of holding an open-ended contract at any age between 27 and 35, perhaps reflecting some form of path-dependence or lower incentives to invest in on-the-job forms of human capital. While differences in the composition of workers remain (through unobserved heterogeneity, which means this evidence is not to be interpreted as causal), we find it suggestive that the "stepping stone" 
Table 2: The probability of working on a open-ended contract between age 27 and age 35

\begin{tabular}{|c|c|c|c|c|}
\hline & \multicolumn{2}{|c|}{ Sample 1} & \multicolumn{2}{|c|}{ Sample 2} \\
\hline & (1) & $(2)$ & $(3)$ & $(4)$ \\
\hline \multirow[t]{2}{*}{ Early starters } & 0.0764 & -0.0029 & 0.0103 & -0.0157 \\
\hline & $(0.0016)$ & $(0.0014)$ & $(0.0022)$ & $(0.0017)$ \\
\hline \multirow[t]{2}{*}{ Average log income } & & 0.1393 & & 0.2093 \\
\hline & & $(0.0004)$ & & $(0.0008)$ \\
\hline \multirow[t]{2}{*}{ Male } & & 0.0258 & & 0.0077 \\
\hline & & $(0.0009)$ & & $(0.0017)$ \\
\hline \multirow[t]{2}{*}{ Age } & & 0.2504 & & 0.0547 \\
\hline & & $(0.0028)$ & & $(0.0046)$ \\
\hline \multirow[t]{2}{*}{ Age squared/100 } & & -0.0037 & & -0.0010 \\
\hline & & $(0.0000)$ & & $(0.0001)$ \\
\hline \multirow[t]{2}{*}{ Fixed-contract at 26} & & 0.0317 & & \\
\hline & & $(0.0015)$ & & \\
\hline \multirow[t]{2}{*}{ Open-ended contract at 26} & & 0.2352 & & 0.1918 \\
\hline & & $(0.0014)$ & & $(0.0017)$ \\
\hline Observations & $3,029,242$ & $3,029,242$ & $1,021,157$ & $1,021,157$ \\
\hline
\end{tabular}

Notes: In sample 1 the "early starters" are people who work at age 25 with a fixed-term contract, while the rest of the sample is people who are unemployed at age 25 . In sample 2 we add the condition that both are employed at age 26. Standard errors clustered by individual workers.

mechanism, if it exists, is rather weak. ${ }^{22}$

\subsection{Experience, human capital, and the slowing down of productivity growth}

As we mentioned in the introduction, labor productivity in Italy has been stagnant for more than two decades (see Figure 1). What is puzzling is that this decline in productivity has occurred despite an overall increase in average years of schooling (see the top right panel of Figure 16), a phenomenon that one would normally associate to an increase in human capital (and hence productivity). ${ }^{23}$ However, there are other components of human capital that may have declined at the same time as average schooling was increasing. In particular, the structural labor market reforms may have contributed to the slowing down of labor productivity growth by reducing onthe-job training and the labor market experience of recent cohorts.

Following the classic theory of human capital, suppose that workers are paid a market rate on their supply of human capital, that human capital of skilled and unskilled workers are perfect substitutes in production, and that schooling, general experience and firm-level experience (tenure) all contribute to human capital. In particular, the Mincerian framework assumes that the human

\footnotetext{
${ }^{22}$ This is also consistent with an early analysis of the nature of fixed-term contracts using Italia survey data by Booth et al. (2002).

${ }^{23}$ Unless schooling is used as a signal, or the quality of education has declined.
} 

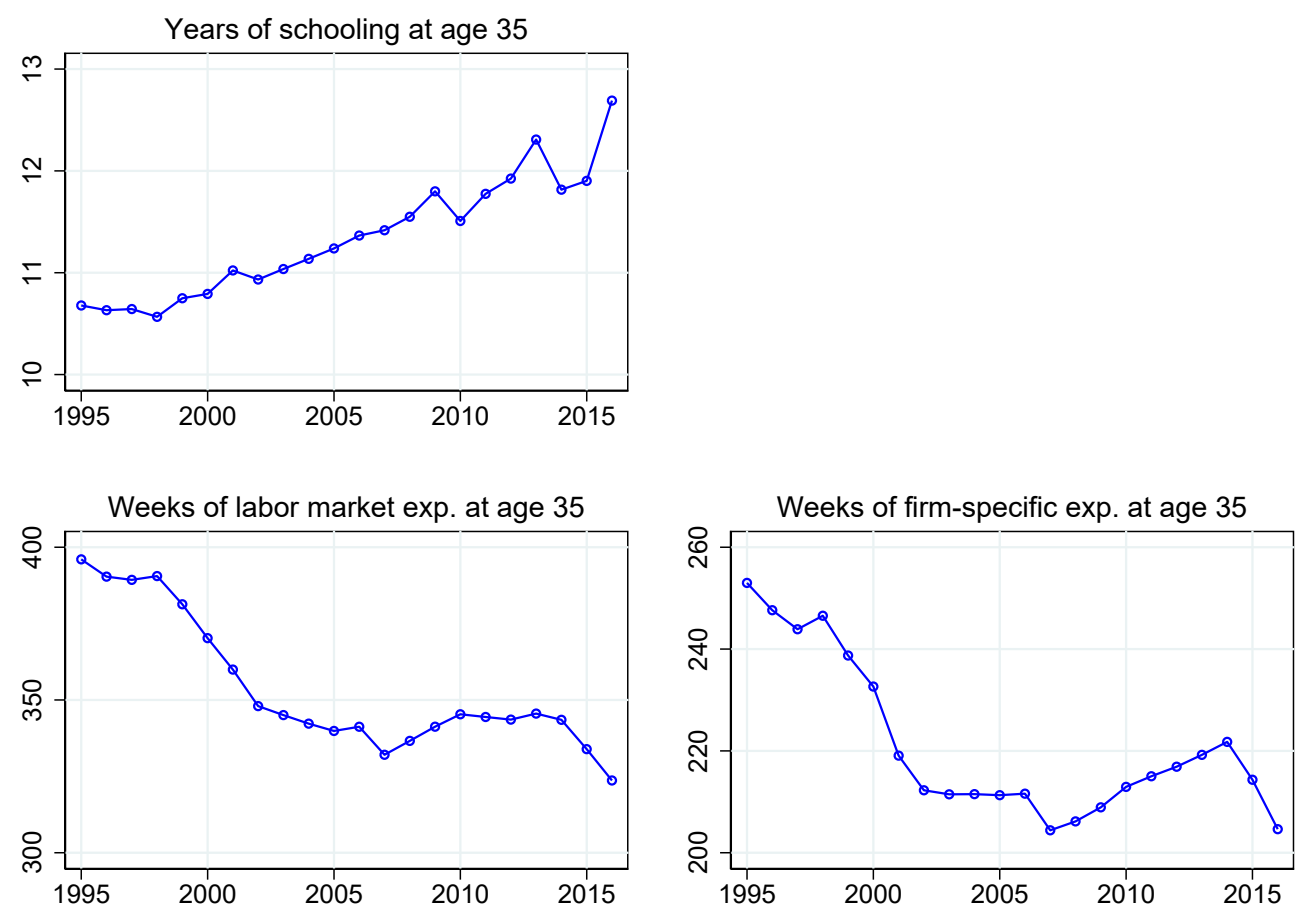

Figure 16: Components of human capital

capital in year $t$ of a worker $i$ born in year $b$ can be described as:

$$
H_{i(b) t}=e^{\phi\left(Q_{i(b) t}\right)} e^{\alpha\left(S_{i(b)}\right)+\beta\left(X_{i(b) t}\right)+\gamma\left(T_{i(b) t}\right)}
$$

where $S_{i(b)}$ is schooling (assumed to be completed by age 25 when people enter the labor market), $X_{i(b) t}$ the number of effective cumulative weeks of experience since age $25, T_{i(b) t}$ the weeks of cumulative tenure with the current employer, and $Q_{i(b) t}$ a set of variables influencing the quality of human capital. Assume for simplicity that schooling affects the growth of human capital linearly, that the functions $\beta($.$) and \gamma($.$) are quadratic in their arguments (as typically assumed in the Mincerian$ regressions), and that the quality of human capital can be adequately captured by a birth cohort effect. Then log earnings can be written as:

$$
y_{i(b) t}=\log \left(w_{t} H_{i(b) t}\right)=\log \left(w_{t}\right)+\phi_{b}+\alpha S_{i(b)}+\beta_{1} X_{i(b) t}+\beta_{2} X_{i(b) t}^{2}+\gamma_{1} T_{i(b) t}+\gamma_{2} T_{i(b) t}^{2}+\varepsilon_{i(b) t},
$$

where the price of a unit of human capital $w_{t}$ is proxied by a time fixed effect, and $\varepsilon_{i(b) t}$ is unobserved heterogeneity (including measurement error, ability, etc.). ${ }^{24}$

Using a within-group strategy to sidestep various forms of omitted variable bias, we can use

\footnotetext{
${ }^{24}$ In the regression we also control for labor supply indicators (weeks worked and part-time status), firm size dummies, and sector dummies.
} 
the INPS data to obtain unbiased estimates of $\beta_{1}, \beta_{2}, \gamma_{1}$ and $\gamma_{2}$. Identification of these parameters comes from labor market interruptions and firm switching, respectively. We then obtain an estimate of the fixed effect $\left(f_{i(b)}=\phi_{b}+\alpha S_{i(b)}\right)$ and hence construct an estimate of the aggregate stock of $(\log )$ human capital of a given cohort at different stages of the life cycle using the Mincer equation estimates of $\beta_{1}, \beta_{2}, \gamma_{1}, \gamma_{2}$, and $f_{i(b)}$, and the average levels of experience and tenure as the cohort ages.

In Figure 17 we plot separately estimates of the quality/schooling component (the term $\phi\left(Q_{i(b) t}\right)+$ $\left.\alpha\left(S_{i(b)}\right)\right)$ and the experience component (the term $\left.\beta\left(X_{i(b) t}\right)+\gamma\left(T_{i(b) t}\right)\right)$ of human capital. Since the first term does not vary over the life cycle, we plot it against the year of entry in the labor market; in contrast, we plot the second term against age for selected birth cohorts. In both cases, we normalize to the value of the cohort born in 1990 and entering the labor market in 2015. The left panel shows that the overall increase in schooling achievement is, for the cohorts entering the labor market between the mid-1990's and the late 2000's, counteracted by a steep decline in the "quality" term, such that the overall quality/schooling component actually declines. However, the level of this component is small compared to the experience component, which we plot in the right panel. Here, we show that cohorts entering in more recent years have human capital profiles systematically below those of older cohorts (i.e., these cohorts have lower predicted human capital). In fact, if we were to extrapolate these profiles to age 55, we calculate that the cohort entering the labor market in 2005 would accumulate $13 \%$ less human capital than the cohort entering in 1995, and $9 \%$ less than the cohort entering in 2000. Our conclusion is that the labor market reforms, shifting younger workers towards atypical contract featuring less attachment to the labor market and to a given employer, contributed to a decline in their stock of human capital in the form of lower levels of general and firm-specific experience, and most likely permanently so. Increases in schooling attainment did not counteract the decline in experience.

\section{Conclusions}

Two key trends characterize the earnings distribution in Italy over the 1985-2016 period: increasing inequality and increasing volatility. These trends are fairly similar for men and women. In the second half of the paper we have argued that the wave of labor market reforms implemented since the late 1990s is the most likely explanation for both trends. The dramatic rise in part-time and fixed-term employment increases inequality in earnings through a dramatic change in the dispersion of annual hours worked across jobs. While dispersion in average hourly earnings also increases, the rise is an order of magnitude less than the dispersion of annual hours. In principle, these changes could represent efficient re-allocation (for example, by facilitating female participation or allowing more flexibility for both firms and workers). However, we show that the emergence of new contractual arrangements brought about by the labor market reforms also increase earnings volatility from one year to the next. If volatility is interpreted as a measure of the uninsurable risk faced by individual workers, then re-allocation has important welfare consequences. The shift 

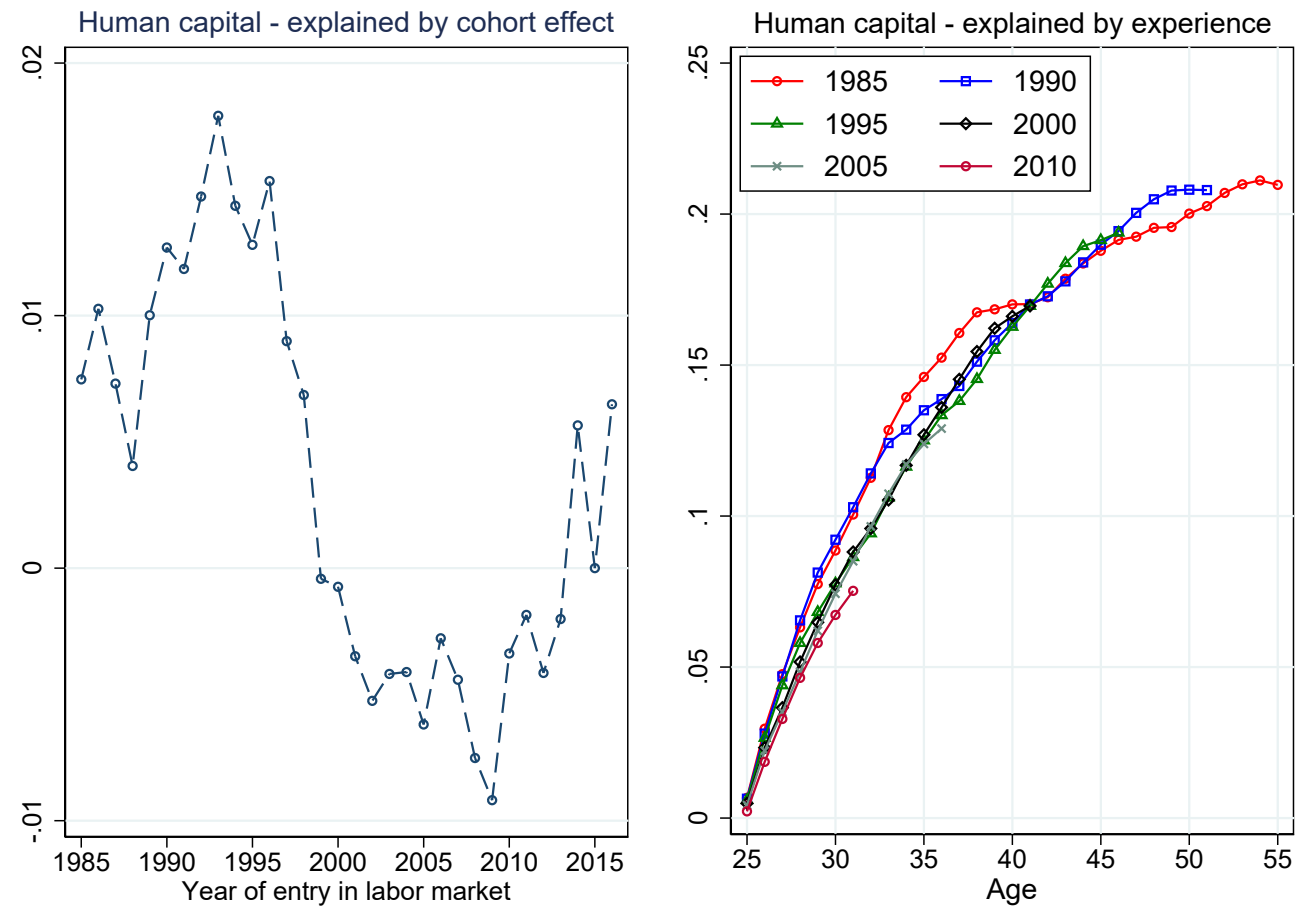

Figure 17: Human capital stock

from open-ended to fixed-term contracts also reduces on-the-job human capital accumulation, both general and firm-specific. This is partly mechanical (due to shorter mean job duration) and partly behavioral (if fixed-term contracts are not always converted to open-ended contracts, both firms and workers have lower incentives to invest in one another). Using a simple Mincer regression framework, we find this indeed to be the case, despite a general increase in schooling attainment. It is plausible that the downward shift in the stock of human capital among younger cohorts may partially be behind the decline in labor productivity observed in Italy since the mid-1990s. This evidence indicates that the policy steps taken in response to the economic slowdown have also indirectly contributed to the decline in labor productivity by slowing the accumulation of human capital. 


\section{References}

Atkinson, A. B., T. Piketty, And E. SAez (2011): "Top Incomes in the Long Run of History," Journal of Economic Literature, 49, 3-71.

Beran, J. And D. Schell (2012): "On robust tail index estimation," Computational Statistics E) Data Analysis, 56, 3430-3443.

Boeri, T. And P. Garibaldi (2007): "Two Tier Reforms of Employment Protection: a Honeymoon Effect?" The Economic Journal, 117, F357-F385.

Booth, A. L., M. Francesconi, and J. Frank (2002): "Temporary Jobs: Stepping Stones or Dead Ends?" The Economic Journal, 112, F189-F213.

Bugamelli, M., S. Fabiani, S. Federico, A. Felettigh, C. Giordano, and A. Linarello (2017): "Back on track? A macro-micro narrative of Italian exports," Questioni di Economia e Finanza (Occasional Papers) 399, Bank of Italy, Economic Research and International Relations Area.

DiNardo, J., N. M. Fortin, And T. Lemieux (1996): "Labor Market Institutions and the Distribution of Wages, 1973-1992: A Semiparametric Approach," Econometrica, 64, 1001-1044.

Finkelstein, M., H. G. Tucker, and J. Alan Veeh (2006): "Pareto tail index estimation revisited," North American actuarial journal, 10, 1-10.

Giordano, R., S. Lanau, P. Tommasino, and P. Topalova (2015): "Does Public Sector Inefficiency Constrain Firm Productivity; Evidence from Italian Provinces," IMF Working Papers 15/168, International Monetary Fund.

Hoffmann, E. B. And D. Malacrino (2019): "Employment time and the cyclicality of earnings growth," Journal of Public Economics, 169, 160 - 171.

Miniaci, R. And G. Weber (1999): "The Italian Recession of 1993: Aggregate Implications of Microeconomic Evidence," Review of Economics and Statistics, 81, 237-249.

Pellegrino, B. And L. Zingales (2017): "Diagnosing the Italian Disease," Working Paper 23964, National Bureau of Economic Research.

Rosolia, A. AND R. TORRIni (2007): "The generation gap: relative earnings of young and old workers in Italy," Temi di discussione (Economic working papers) 639, Bank of Italy, Economic Research and International Relations Area.

TeAlDi, C. (2011): "Typical and atypical employment contracts: the case of Italy," Questioni di Economia e Finanza (Occasional Papers) 39456, Munich Personal RePEc Archive. 


\section{Appendix}

\section{A.1 Other forms of employment: public sector and self employ- ment}

One of the limitations of the INPS data is that it does not cover public sector workers or self employed. In this section, we use the Survey of Household Income and Wealth (SHIW) to explore these other forms of employment and to gauge their potential impact were our statistics derived on the full population of workers. The SHIW is conducted by the Bank of Italy and is a representative cross section of households and workers. Since 1989, SHIW follows a rotating sample of panel households. These household are sampled once every two years.

To complement our analysis, we use three main features of the survey data. First, the survey identifies self employment and self employment income. The data further indicate whether the worker is a sole proprietor, a free lance worker, or a "member of the professions". Second, the data include a variable for the industry of the worker. These are only broad industry but they indicate whether the worker is a private or a public employee. Third, for all three categories of workers there is a variable measuring the self reported status of the worker. Fourth, there is a variable on contract type and whether work is supplied on a full time or part time basis.

The first question is how often do workers transition between four labor market states: employment with a permanent contract, employment with a temporary or a fixed-term contract, self employment, and non-employment. We measure the 2-year probability of observing a worker in each one of these states switch to any other states. We estimate the probabilities on workers $25-55$ years old, and separately for men and women but pooling over all the years since 2000. Using these estimates we find the unique "generator matrix" that matches the observed transition probabilities. A generator matrix is a matrix in which each row includes the Poisson arrival rate of jumps from the row state to the column state, and has negative values on the diagonal so that the rows add up to one. This matrix defines a continuous time Markov chain and allows us to make predictions on the conditional state distribution of workers at any horizon given initial conditions.

Figure A.1 shows the conditional probability of being in each labor market state at every horizon up to 20 years, for women and men separately (panel (a) for women, panel (b) for men). The figures reveal several facts. One is that a fixed-term contract status is more likely to lead to

non employment. For both women and men, the probability of a fixed-term contract holder to have an open-ended contract within 5 years is $50 \%$, and to have a fixed-term contract $15 \%$. But women with fixed-term contract have a 30\% probability of being non employed within 5 years, compared to $22 \%$ for men. The difference is captured by men's higher probability of being self employed. Self employment is considerably less persistent status for women. The probability of being self employed after 5 years for a self employed woman is only $50 \%$ compared to $75 \%$ for men. Similarly, non-employment status is more likely to persist for women: $75 \%$ of non employed women are non employed 5 years later compared to only $50 \%$ for men. We conclude the following: workers 
in open-ended jobs, both men and women, are not likely to transition to a fixed-term contract, while workers in fixed-term employment often end up in an open-ended contract. Furthermore, the "temporary" contract seems to serve its purpose better for men than for women. Lastly transitions into self employment are rare. Self employed men are likely to transition directly into a permanent contract, while self employed women are equally likely to be employed in a temporary contract which suggests that self employment serves a different purpose for men and women.

The second question is: how often do workers transition between private and public sector jobs? We apply the same method of measuring transition probabilities and extrapolating under the continuous-time Markov chain assumption, but this time to employment in the private sector, the public sector, self-employment, and non employment. Figure A.2 shows the estimated probabilities. Both women and men employed in the privates sector have a low probability of transitioning to the public sector. The probability of a worker employed in the private sector to be employed in the public sector after 20 years is $21 \%$ for women and $16 \%$ for men. Transitions in the opposite direction are much more common: $22 \%$ of women and $24 \%$ of men in public sector jobs transition to private sector jobs after 5 years, and this number grows to $30 \%$ and $44 \%$ after 20 years. This is likely due to the gradual reduction in the size of the Italian public sector over the sample period.

\section{A.2 Top income share estimation in right-censored data}

This section describes the procedure of estimating top income shares in top-coded data and implements it to the INPS data. The basic idea is the following. Let $F(y)$ be the true cumulative distribution function of earnings. If the distribution has a Pareto tail, that is, there is a value $\underline{y}$ such that for all earnings $y>\underline{y}$ earnings are Pareto distributed,

$$
1-F(y)=(1-F(\underline{y}))\left(\frac{y}{y}\right)^{-\alpha} .
$$

The parameter $\alpha>0$ is the Pareto tail index. We assume that $y$ is smaller then the top coding threshold, and thus the mean income of workers below it, $E[y \mid y<\underline{y}]$, can be reliably estimated with a simple mean, and the probability $F(\underline{y})$ estimated as the share of observation smaller than

$\underline{y}$. Inverting the expression for the tail distribution, we can define the quantile function for all probabilities $P>F(\underline{y})$ as

$$
Q(P)=\mathrm{y}\left(\frac{1-P}{1-F(\underline{y})}\right)^{-\frac{1}{\alpha}} .
$$

Furthermore, if $\alpha>1$, the mean income above the $P$ quantile is

$$
E[y \mid y>Q(P)]=\frac{\alpha}{\alpha-1} Q(P) .
$$

The share of earnings that goes to the top $(1-P)$ quantiles can then be expressed as: 

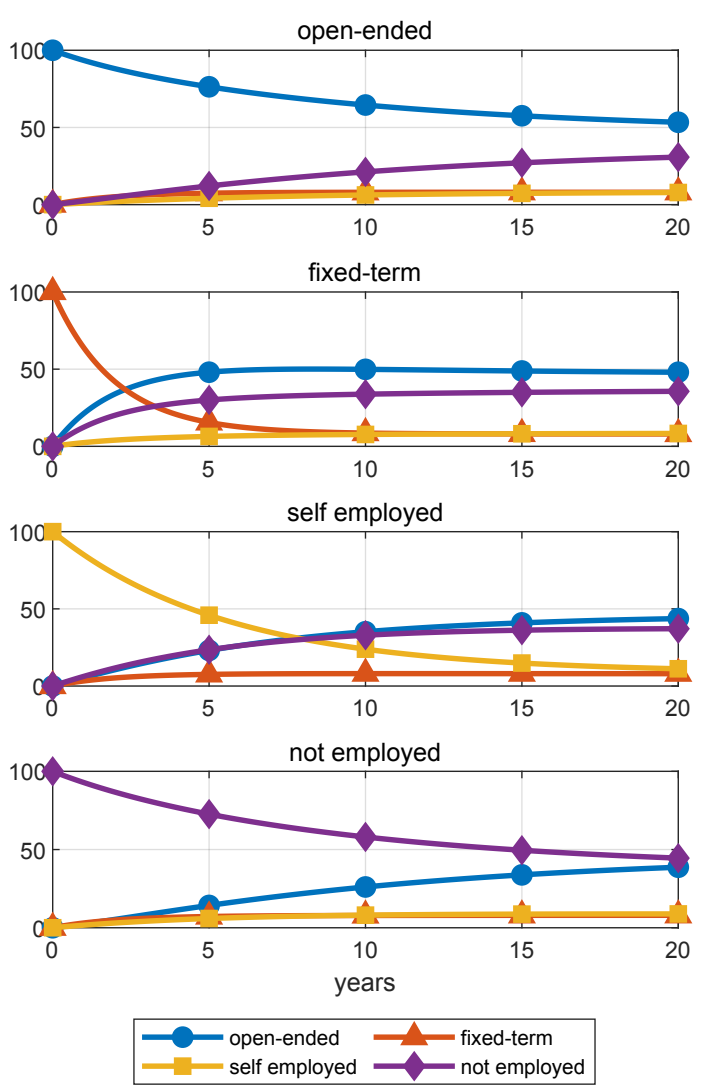

(a) women
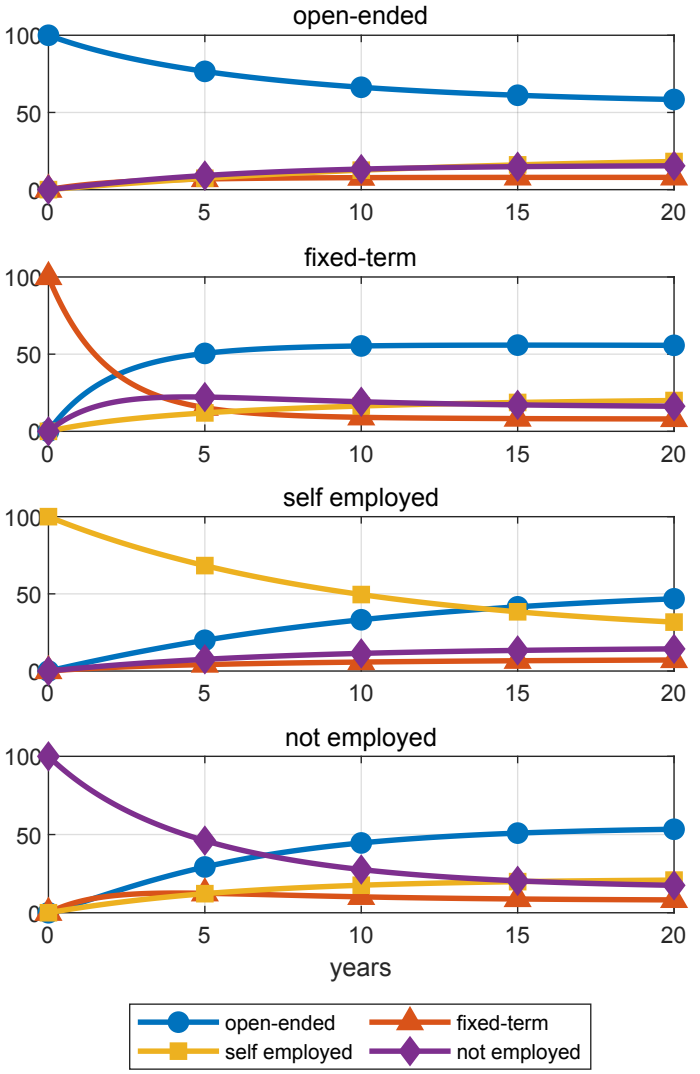

(b) men

Figure A.1: Transition probabilities by horizon

Notes: Each graph shows the probability of a worker in a certain state (open-ended, fixed-term, self employed, not employed), which is specified in the title, to be in each of the states after a given number of years. Probabilities calculated using a continuous-time Markov chain with a fixed transition matrix. The transition matrix is estimated using two-years changes in work status for 25-55 year old in SHIW pooled sample, 2000-2016. 

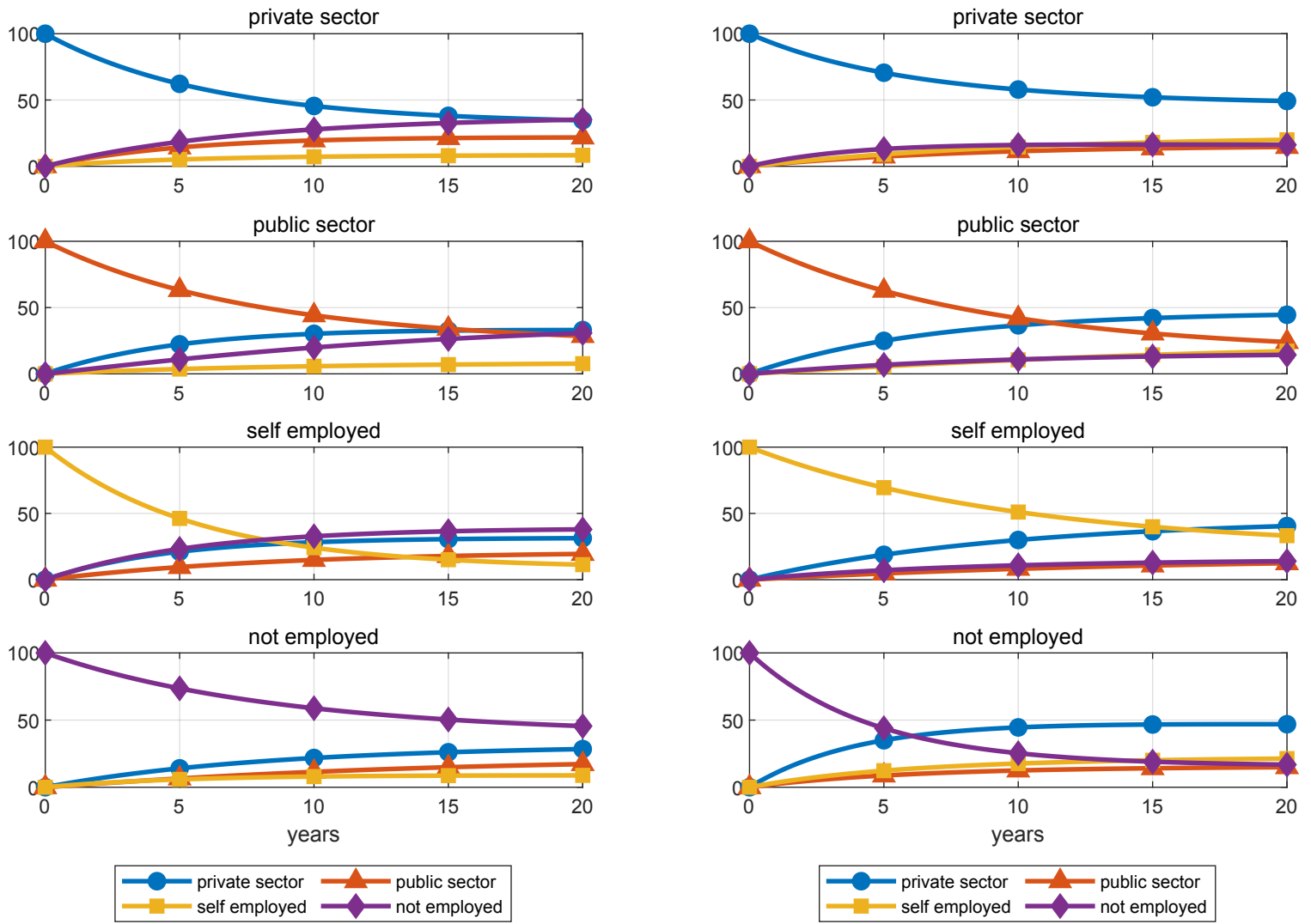

(a) women

(b) men

Figure A.2: Transition probabilities between sectors by horizon

Notes: Each graph shows the probability of a worker in a certain state (private sector, public sector, self employed, not employed), which is specified in the title, to be in each of the states after a given number of years. Probabilities calculated using a continuous-time Markov chain with a fixed transition matrix. The transition matrix is estimated using two-years changes in work status for 25-55 year old in SHIW pooled sample, 2000-2016. 
$S_{(1-P)}=\frac{(1-P) E[y \mid y>Q(P)]}{\underline{\mathrm{F} E[y \mid y \leq \mathrm{y}]+(1-F(\underline{y})) E[y \mid y>\mathrm{y}]}}=\frac{\alpha(1-P) \underline{\mathrm{y}}}{(\alpha-1) \mathrm{F}(\underline{y}) E[y \mid y \leq \mathrm{y}]+\alpha(1-F(\underline{y})) \underline{\mathrm{y}}}\left(\frac{1-P}{1-F(\underline{y})}\right)^{-\frac{1}{\alpha}}$

Equation (A.1) provides a closed form expression for the top income share for any choice of quantiles given an estimate of the Pareto parameter $\alpha$, the conditional mean of the truncated distribution $E[y \mid y \leq \mathrm{y}]$ and the probability of observing income below the top code $F(\underline{y})$.

The parametric expression in equation A.1 relies on the Pareto-tail assumption. Is this assumption reasonable in the Italian context? A typical approach for visually inspecting tail distributions is a Zipf (or log-log) plot: a plot of the logarithm of the survival function $(1-F(y))$ against $\log (y)$. If the data generating distribution has a Pareto tail, the relationship should be approximately linear at high incomes. Moreover, the absolute value of the slope of the linear line is an estimate of $\alpha$, the tail index of the Pareto distribution. Figure A.3 shows the distribution of earnings for selected years $(1985,1995,2005$, and 2015) between the 90th and 99th earnings percentiles (which are below the top-coding threshold, and therefore do not suffer from bias). The Zipf plots indeed appear to be close to linear, and thus support the Pareto-tail assumption.

\section{A.2.1 Estimating the Pareto-tail index}

We adapt four methods of estimating Pareto-tail index from right-censored data:

1. Maximum Likelihood (ML)

2. Quantile Slope (QL)

3. Kernel Density Slope (KDS)

4. Probability Integral Transform Statistic (PITS)

For all methods we assume that earnings $\tilde{y}$ are Pareto distributed for values above a lower threshold, $\tilde{y} \geq \underline{y}$, and censored above an upper threshold, $\bar{y}$, so that the observed data is

$$
y= \begin{cases}\tilde{y} & \text { if } \tilde{y}<\bar{y} \\ \bar{y} & \text { if } \tilde{y} \geq \bar{y}\end{cases}
$$

This implies that conditional on earnings being above the lower threshold $y \geq \underline{y}$, the cumulative distribution function is

$$
F(y)= \begin{cases}1-\left(\frac{y}{y}\right)^{-\alpha} & \text { if } y<\bar{y} \\ 1 & \text { if } y \geq \bar{y}\end{cases}
$$

We consider estimators based on $\underline{N}$ independent observations $y_{i}, i=1, \ldots, \underline{N}$, which are greater or equal to the lower threshold. Without loss of generality, we also assume that the earnings observations are in increasing order, and the last $\bar{N}$ are censored. 


\section{A.2.2 Maximum Likelihood}

This is the theoretically most efficient method. The likelihood of observation $y_{i}$ is

$$
l\left(\alpha, y_{i}\right)= \begin{cases}\frac{\alpha}{y}\left(\frac{y_{i}}{\underline{y}}\right)^{-\alpha} & \text { if } y_{i}<\bar{y} \\ \left(\frac{\bar{y}}{\underline{y}}\right)^{-\alpha} & \text { if } y_{i}=\bar{y}\end{cases}
$$

The log-likelihood function is

$$
L\left(\alpha, y_{i}\right)=(\underline{N}-\bar{N}) \log \alpha-\sum_{i=1}^{\underline{N}-\bar{N}} \log y_{i}-\alpha \sum_{i=1}^{\underline{N}}\left(\log y_{i}-\log \underline{y}\right) .
$$

The ML estimator is the value of $\alpha$ that satisfies the first order condition,

$$
\hat{\alpha}_{M L}=\frac{\underline{N}-\bar{N}}{\sum_{i=1}^{N}\left(\log y_{i}-\log \underline{y}\right)}=\frac{\underline{N}-\bar{N}}{\sum_{i=1}^{\underline{N}-\bar{N}} \log y_{i}+\bar{N} \log \bar{y}-\underline{N} \log \underline{y}} .
$$

\section{A.2.3 Quantile Slope}

The Quantile Slope (QS) estimator uses the sample quantiles and the slope of the Zipf plots to estimate the Pareto-tail index. The quantile function for a given probability $P$ is defined as

$$
Q(P)=\inf \{y: F(y) \geq P\}
$$

In the case of a censored random variable with a Pareto tail, we can express the quantile function as

$$
Q(P)= \begin{cases}\underline{y}(1-P)^{-\frac{1}{\alpha}} & \text { if } P<F(\bar{y}), \\ \bar{y} & \text { if } P \geq F(\bar{y}) .\end{cases}
$$

Let $P_{1}<P_{2}<\ldots<P_{J}$ be a set of numbers $P_{j} \in(0, F(\bar{y}))$. The sample quantile is $Q_{j}$ is defined as

$$
Q_{j}=y\left\lfloor\underline{N} P_{j}\right\rfloor+1,
$$

and converges in probability to $Q\left(P_{j}\right)$ as $\underline{N}$ increases.

We assume that $P_{J}$ is small enough so that $Q_{J}<\bar{y}$. The quantile slope estimator is the absolute value of the slope coefficient in the regression of $\log \left(1-P_{j}\right)$ on $\log Q_{j}$. A closed form expression for the Quantile Slope estimator of $\alpha$ is

$$
\hat{\alpha}_{Q S}=-\frac{\sum_{j=1}^{J}\left(\log Q_{j}-\frac{1}{J} \sum_{k=1}^{J} \log Q_{k}\right)\left(\log \left(1-P_{j}\right)-\frac{1}{J} \sum_{k=1}^{J} \log \left(1-P_{k}\right)\right)}{\sum_{j=1}^{J}\left(\log Q_{j}-\frac{1}{J} \sum_{k=1}^{J} \log Q_{k}\right)^{2}} .
$$




\section{A.2.4 Kernel Density Slope}

The Kernel Density Slope (KDS) estimator operates on a similar principle as the QS estimator, but uses the slope of the density function instead of the the quantile function. Let $x=\log y$ be the logarithm of earnings. The CDF of $x$ is

$$
F_{X}(x)= \begin{cases}1-\underline{y}^{\alpha} e^{-\alpha x} & \text { if } x<\log \bar{y} \\ 1 & \text { if } x \geq \log \bar{y} .\end{cases}
$$

The density of $x$, if $x<\log \bar{y}$, is given by

$$
f(x)=\alpha \underline{y}^{\alpha} e^{-\alpha x} .
$$

For a given $x<\log \bar{y}$, the density function can be estimated non-paramterically using a kernel function $K$ and bandwidth $h$, according to

$$
\hat{f}(x)=\frac{1}{\underline{N}-\bar{N}} \sum_{i=1}^{\underline{N}-\bar{N}} K\left(\frac{x-x_{i}}{h}\right)
$$

Note that this kernel density estimator is generally inconsistent for censored data because the density does not exist at the thresholds $y$ and $\bar{y}$. However, for values of $x$ far enough from the thresholds and a small enough bandwidth is can perform well.

Let $x_{1}<x_{2}<\ldots<x_{J}$ be as set of points in which the density can be reliably estimated. Then the KDS estimator of the Pareto-tail index is the slope of a regression of $\log \hat{f}(x)$ on $x$,

$$
\hat{\alpha}_{K D S}=-\frac{\sum_{j=1}^{J}\left(x_{j}-\frac{1}{J} \sum_{k=1}^{J} x_{k}\right)\left(\log \hat{f}\left(x_{j}\right)-\frac{1}{J} \sum_{k=1}^{J} \log \hat{f}\left(x_{k}\right)\right)}{\sum_{j=1}^{J}\left(x_{j}-\frac{1}{J} \sum_{k=1}^{J} x_{k}\right)^{2}} .
$$

\section{A.2.5 Probability Integral Transform Statistic}

The Probability Integral Transform Statics (PITS) uses the method of moments to estimate the Pareto index. Finkelstein, Tucker, and Alan Veeh (2006) suggest that a PITS estimator for noncensored data and discuss its properties. They show that under a certain type of deviation this estimator is more robust than the ML estimator and other commonly used estimators. Here, we adapt the estimator for the use in censored data.

We define a transformation $G(y, a)$ by

$$
G(y, a)=\frac{(1+t)}{1+t \underline{y}^{a(1+t)} \bar{y}^{-a(1+t)}}\left(\frac{y}{y}\right)^{-a t},
$$

where $t>0$ is a tuning parameter. The expected value of $\left(\frac{y}{y}\right)^{-\alpha t}$ is 


$$
E\left[\left(\frac{y}{y}\right)^{-\alpha t}\right]=\int_{\underline{y}}^{\bar{y}} \alpha \underline{y}^{\alpha(1+t)} y^{-\alpha(1+t)-1} d y+\underline{y}^{\alpha(1+t)} \bar{y}^{-\alpha(1+t)}=\frac{t}{1+t} \underline{y}^{\alpha(1+t)} \bar{y}^{-\alpha(1+t)}+\frac{1}{1+t}
$$

which means that the expected value of $G(y, \alpha)$ is equal to 1 . The PITS estimator relies on this property and is defined implicitly as the solution to the equation

$$
\frac{1}{\underline{N}} \sum_{i=1}^{\underline{N}} G\left(y_{i}, \hat{\alpha}_{P I T S}\right)=1
$$

\section{A.2.6 Comparison}

All four methods presented here are consistent estimators of the Pareto-tail index. Yet each one has unique characteristics that may make it attractive for a given application. The Quantile Slope and Kernel Density Slope rely on intuitive methods and map in a simple and transparent way to the data. They effectively ignore all the information that is contained in the censored observations. In addition, the sampling points $\left(P_{j}\right.$ 's and $x_{j}$ 's) are arbitrary and their choice may affect the estimates. This becomes a bigger concern when the KDS method is applied on sparse data as the estimates may include a considerable bias. The KDS method also require the choice of a kernel function and a bandwidth which makes it a more complicated procedure.

The Maximum Likelihood estimator is the most efficient and is also simple to calculate. However, Finkelstein et al. (2006), and Beran and Schell (2012) that the ML estimator is not robust when the tail is only approximately Pareto distributed. Finkelstein et al. (2006) suggest using the PITS estimator, which is adapted here for the use with censored data. The PITS estimator delivers more robustness than the ML estimator when the Pareto distribution is mixed with another "noise" distribution, at a mild cost in efficiency.

To illustrate these differences, we apply each estimator to 100 bootstrapped samples of the INPS 2015 earnings data. We set the lower threshold at the 0.9 sample quantile to focus on the top $10 \%$ of income. INPS top code daily earnings and report the annual earnings. Since annual earnings records smaller than the maximal top-coded threshold (365 times the daily threshold) may be partially top coded, we set the upper threshold for the estimators at the 0.99 sample quantile. For the QS method we need to choose the cumulative probability points for estimation of the quantiles. We pick 100 equally distanced points between 0 and 0.85 . For the kernel density we use the Epanechnikov kernel with a bandwidth of 0.05 and 100 equally spaced sample points in log earnings, between the 90th percentile and the 98.5 percentile. For the tuning parameter of the PITS estimator we pick $t=0.5$.

Figure A.4 shows bootstrap replication histograms for the four methods. All four methods keep the dispersion of estimates low. Bootstrapped standard deviations range from 0.0089 for the ML estimator and 0.0189 for the KDS estimator. Due to different reasons discussed in this appendix, the point estimates are statistically different. The economic implications are not large though; 

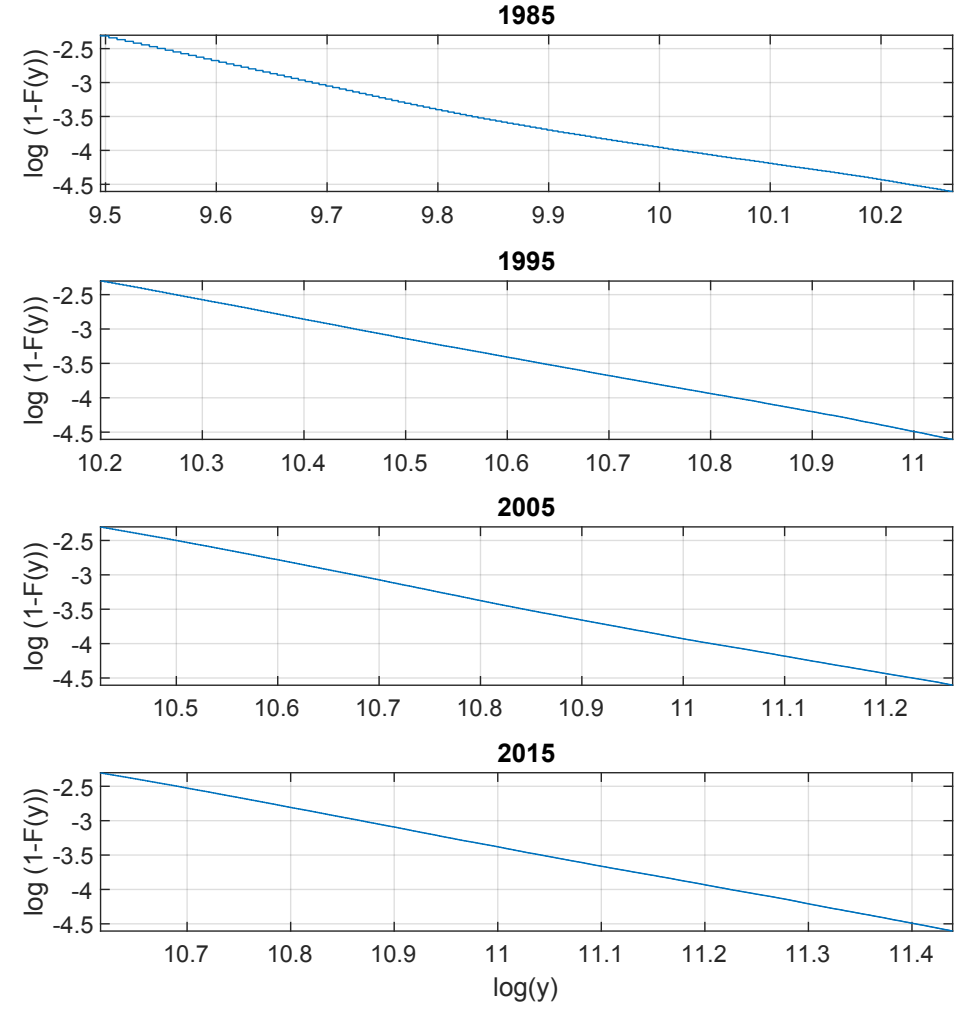

Figure A.3: The tail of the income distribution by year

Notes: The graphs show the logarithm of the survival function for the years 1985, 1995, 2005, and 2015. The graphs show the distribution from the 0.9 sample quantile to the 0.99 sample quantile. The horizontal axis is the logarithm of earnings in 2010 euros.

the top $1 \%$ share is $6.63 \%$ based on the PITS estimator (lowest index) is $6.43 \%$ based on the QS estimator (highest index).

Our estimate of the Pareto-tail index for all years in the sample is reported in Figure A.5. The shaded area is the $95 \%$ confidence interval based on 100 bootstrap replications. 
(a) ML

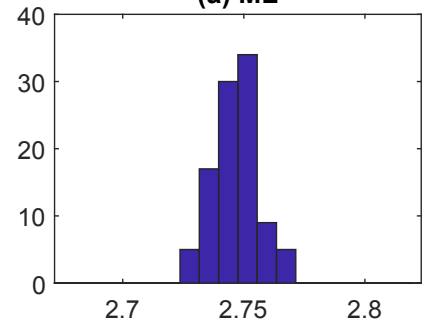

(c) KDS

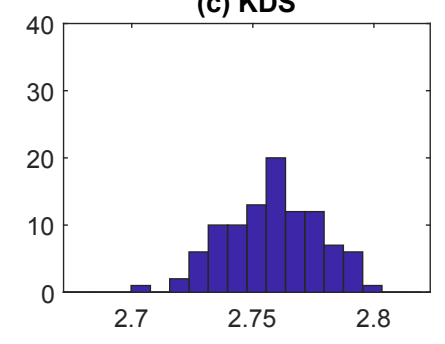

(b) QS

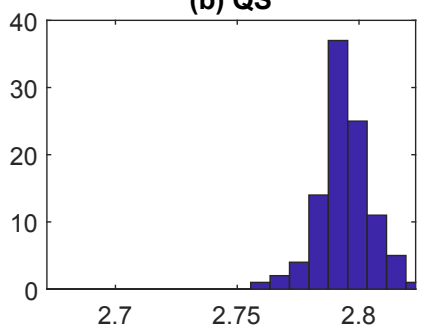

(d) PITS

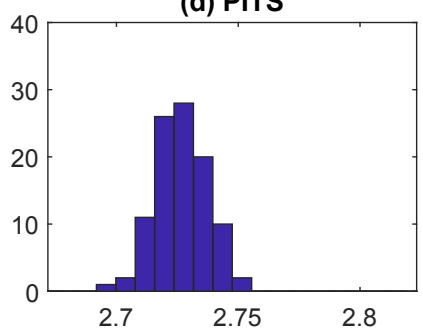

Figure A.4: Bootstrap replication histograms for Pareto-tail index estimates - earnings in 2016

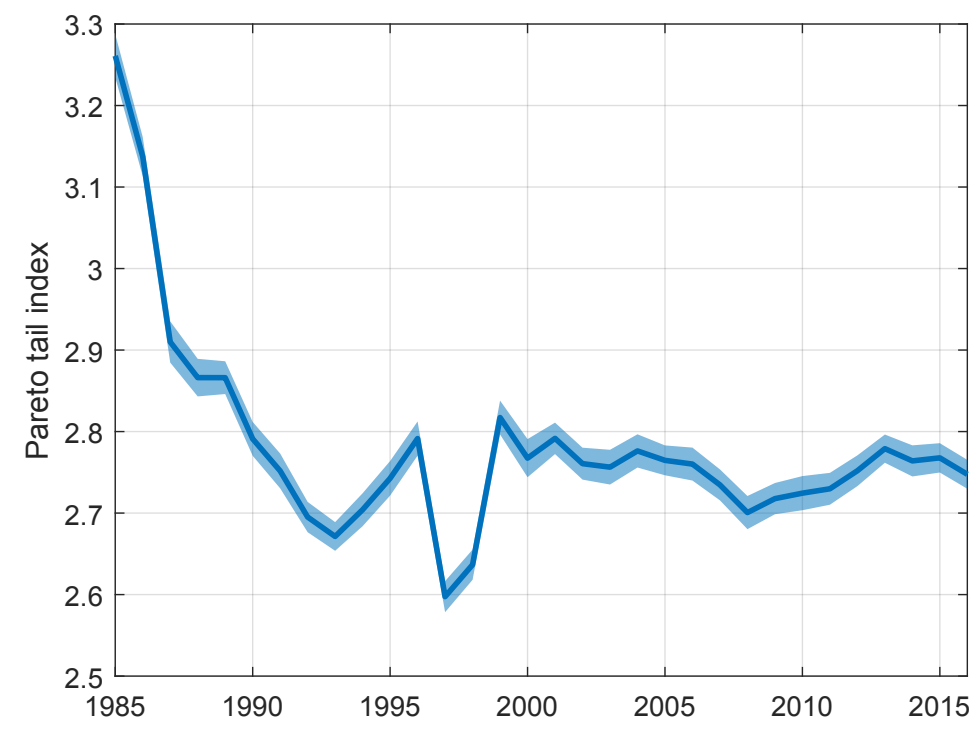

Figure A.5: Pareto tail index estimates 


\section{A.3 Additional Figures}

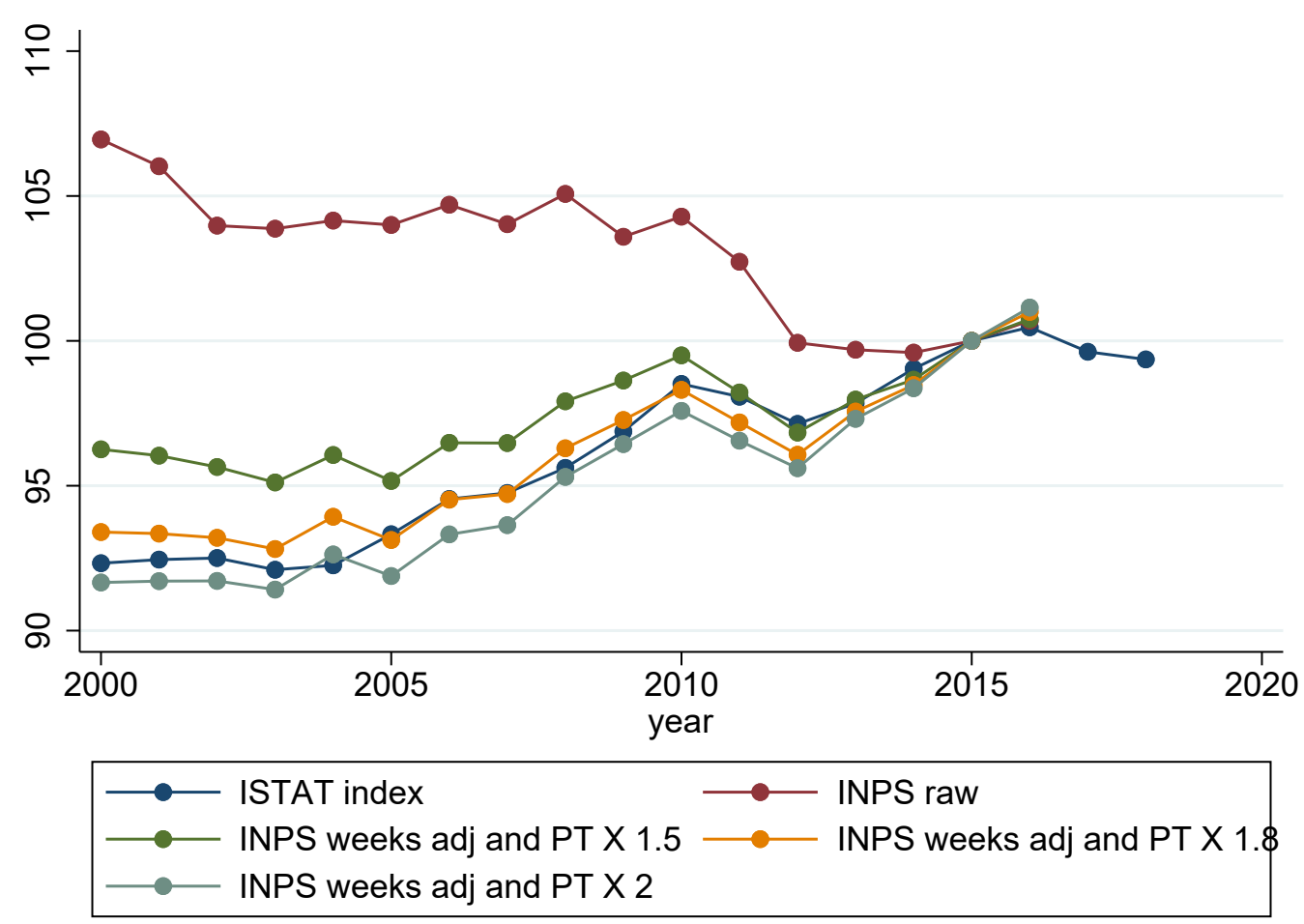

Figure A.6: Closing the gap in the evolution of earnings from 2000 to 2016 (index, 2015=100) 

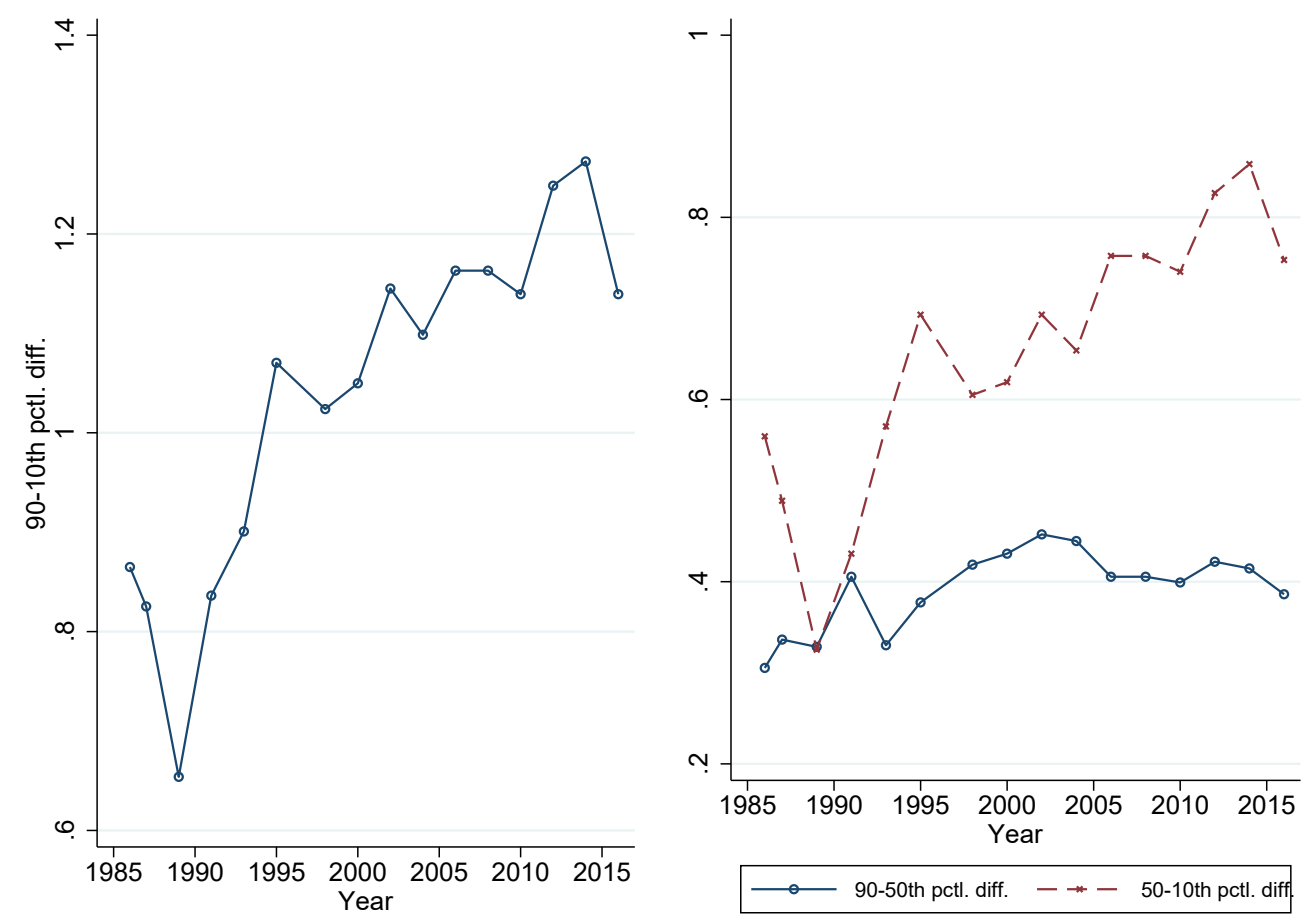

Figure A.7: Inequality for public employees, SHIW

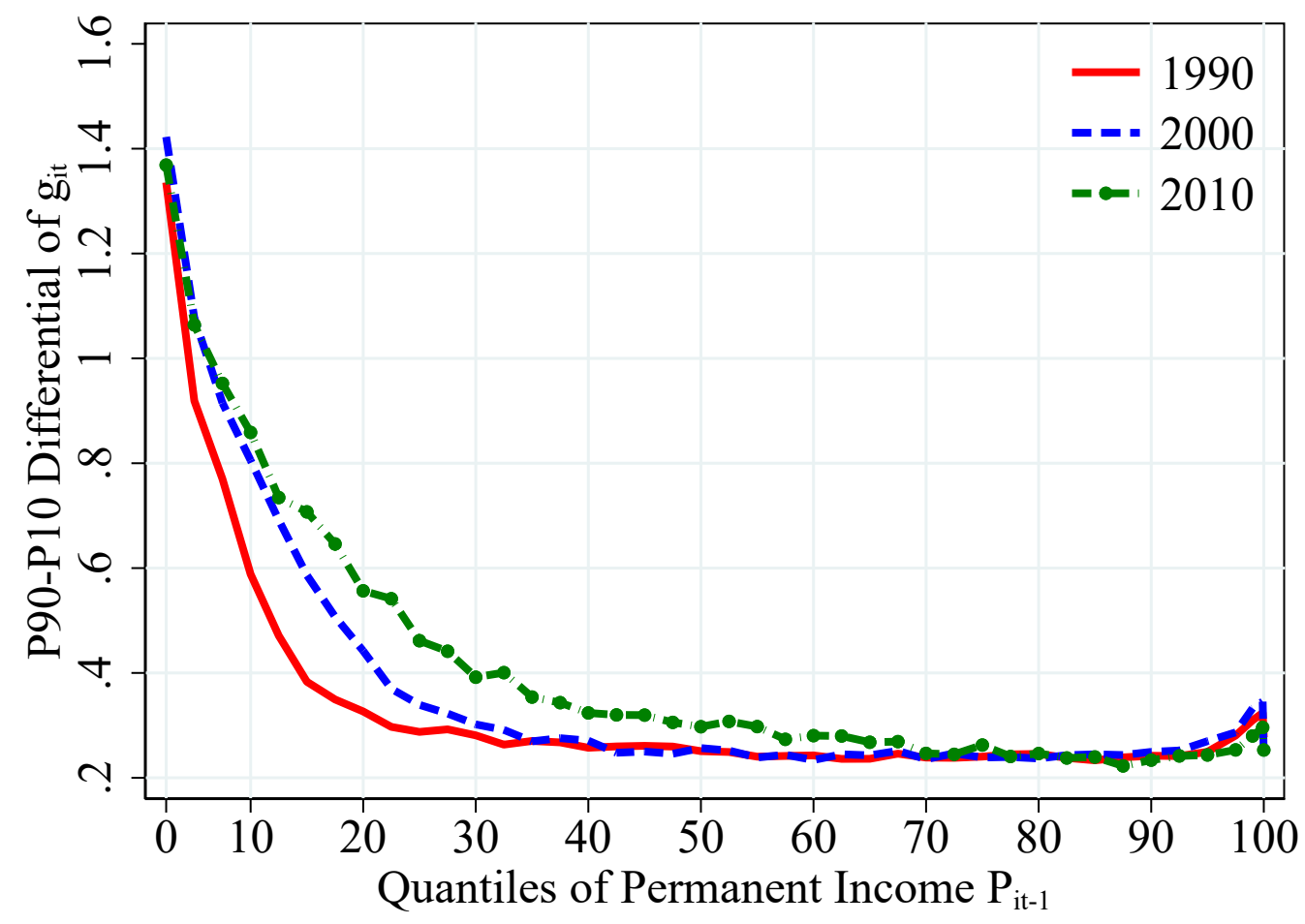

Figure A.8: Volatility by permanent income for selected years 


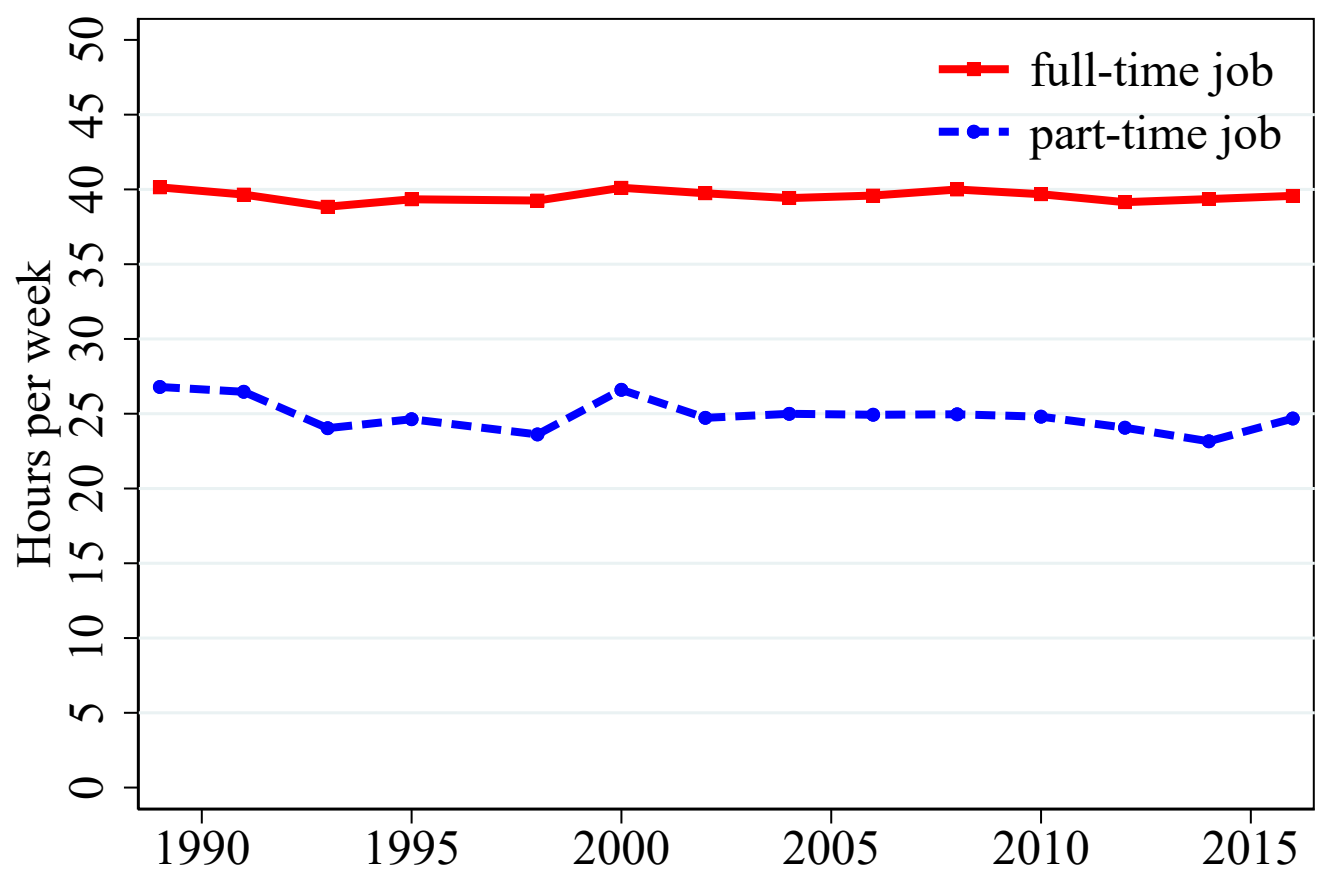

Figure A.9: Hours per week by employment status

Notes: The lines show average hours of work per week by full- and part-time status based on SHIW. The sample is restricted to 25-55 year old workers, and it excludes the self-employed.

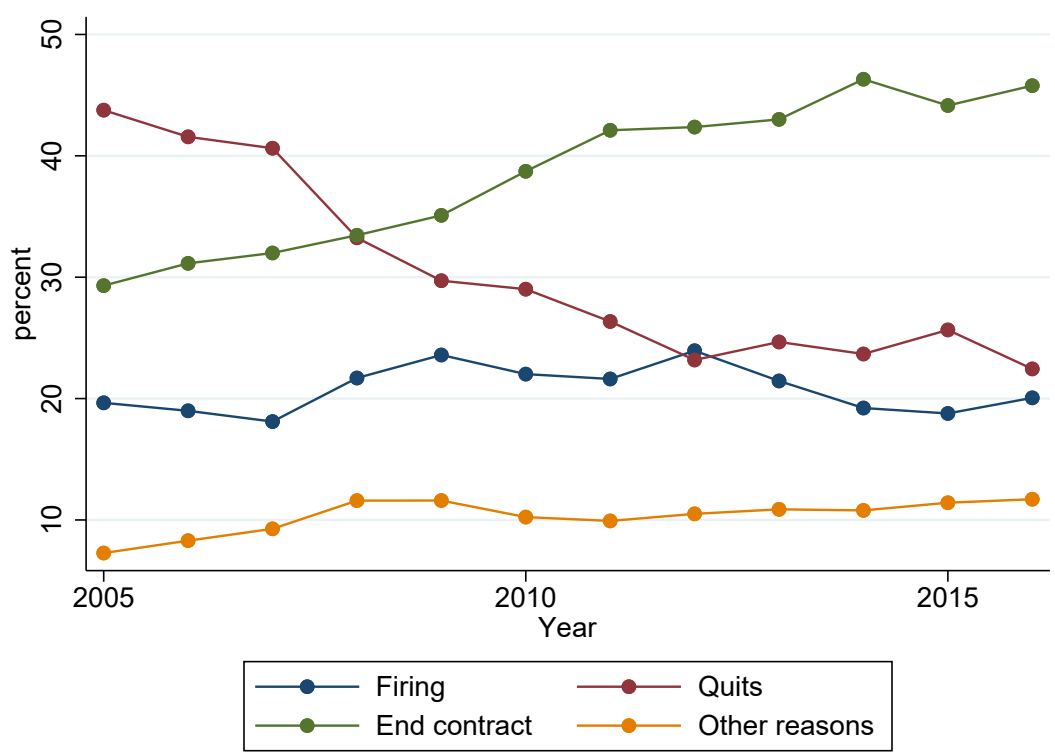

Figure A.10: Cause of separations 